Atmos. Chem. Phys., 13, 10591-10607, 2013

www.atmos-chem-phys.net/13/10591/2013/

doi:10.5194/acp-13-10591-2013

(c) Author(s) 2013. CC Attribution 3.0 License.

\title{
Quantifying tracer transport in the tropical lower stratosphere using WACCM
}

\author{
M. Abalos ${ }^{1}$, W. J. Randel ${ }^{2}$, D. E. Kinnison ${ }^{2}$, and E. Serrano ${ }^{1}$ \\ ${ }^{1}$ Universidad Complutense de Madrid, Depto. de Meteorología y Geofísica, Madrid, Spain \\ ${ }^{2}$ National Center for Atmospheric Research, Boulder, Colorado, USA
}

Correspondence to: M. Abalos (mabalosa@ fis.ucm.es)

Received: 24 April 2013 - Published in Atmos. Chem. Phys. Discuss.: 21 May 2013

Revised: 3 October 2013 - Accepted: 5 October 2013 - Published: 1 November 2013

\begin{abstract}
The zonal mean transport of ozone and carbon monoxide $(\mathrm{CO})$ near the tropical tropopause is investigated using the Whole-Atmosphere Community Climate Model version 4 (WACCM4). The variability in temperature, ozone and $\mathrm{CO}$ in the model shows good agreement with satellite and balloon observations. Modeled temperature and tracers exhibit large and closely coupled annual cycles in the tropical lower stratosphere, as in the observations. The thermodynamic and tracer budgets in the model are analyzed based on the Transformed Eulerian Mean (TEM) framework on log-pressure coordinates and also using the isentropic formulation. Results show that the coupled seasonal cycles are mainly forced by tropical upwelling over altitudes with large vertical tracer gradients, in agreement with previous observational studies. The model also allows explicit calculation of eddy transport terms, which make an important contribution to ozone tendencies in the tropical lower stratosphere. The character of the eddy fluxes changes with altitude. At higher levels ( $\sim 2 \mathrm{~km}$ above the cold point tropopause), isentropic eddy transport occurs during winter and spring in each hemisphere in the sub-tropics, associated with transient Rossby waves acting on strong background latitudinal gradients. At lower altitudes, close to the tropical tropopause, there is a maximum in horizontal eddy transport during boreal summer associated with the Asian monsoon anticyclone. Subseasonal variability in ozone and $\mathrm{CO}$, tied to fluctuations in temperature, is primarily driven by transient tropical upwelling. In isentropic coordinates, the overall tracer budgets are similar to the log-pressure results, highlighting crossisentropic advection as the main term in the time-mean balance, with large seasonality above the tropopause. However, in isentropic coordinates the tracer variability is largely re-
\end{abstract}

duced on both seasonal and sub-seasonal timescales, because tracer fluctuations are highly correlated with temperature (as a response to upwelling).

\section{Introduction}

The tropical tropopause layer (TTL) acts as a boundary condition for the chemical composition of the stratosphere, such that the temperature and tracer concentrations of the air just above the tropical tropopause affect the composition of the entire stratosphere (e.g. Fueglistaler et al., 2009). In addition, concentrations of radiatively active trace gases in the TTL and the tropical lower stratosphere have a particularly large impact on radiative forcing, influencing surface climate (Riese et al., 2012). Hence, it is crucial for chemistryclimate models to correctly represent tracer behavior in this region in order to simulate present and future climate (Gettelman et al., 2010). The spatial distribution and temporal variability of constituents in the tropical lower stratosphere is mostly determined by transport processes, along with chemical sources and sinks. Some of the key issues regarding tracer transport in this region remain poorly quantified, such as the relative importance of vertical advection by largescale tropical upwelling and irreversible mass exchange between the tropics and the extra-tropics. Observational and modeling studies suggest that the tropical lower stratosphere above $\sim 20 \mathrm{~km}$ acts as a reservoir, in which chemical species are in partial isolation from the extra-tropics (Plumb, 1996). Within this region, tracer transport is dominated by largescale ascent associated with the Brewer-Dobson circulation (Plumb, 2002; Shepherd, 2007). The barriers separating this

Published by Copernicus Publications on behalf of the European Geosciences Union. 

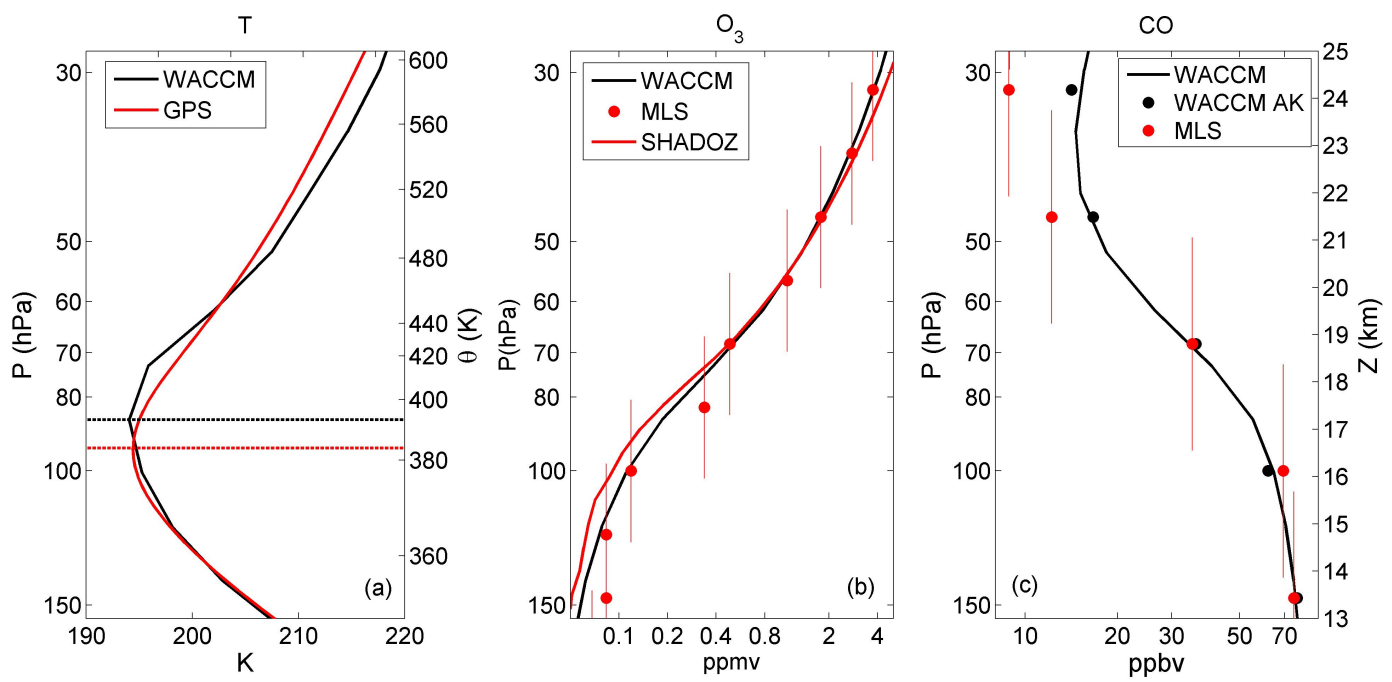

Fig. 1. Vertical structure of annual mean temperature (a), ozone (b) and CO (c) in WACCM and in observations averaged over the tropics $\left(18^{\circ} \mathrm{S}-18^{\circ} \mathrm{N}\right.$ for WACCM, $18.75^{\circ} \mathrm{S}-18.75^{\circ} \mathrm{N}$ for MLS and $20^{\circ} \mathrm{S}-20^{\circ} \mathrm{N}$ for GPS). Solid black line: WACCM, solid red: GPS in (a) and SHADOZ in (b), red dots: MLS, black dots in (c): WACCM with MLS CO averaging kernel. The vertical red bars indicate the width of the MLS averaging layers. For reference, the location of annual mean isentropic levels in WACCM is indicated on panel (a) and the approximate altitude on panel (c), calculated as $Z=-H \ln \left(P / P_{0}\right)$, with $P_{0}=1000 \mathrm{hPa}$ and $H=7 \mathrm{~km}$. The ozone and CO scales are logarithmic in order to better represent the sharp vertical gradients. Horizontal dashed lines in panel (a) indicate the location of the annual mean cold point tropopause in WACCM (black) and in GPS observations (red).

tropical upwelling region from the mid-latitudes, where isentropic mixing dominates over slow poleward advection, are not static but move seasonally towards the summer hemisphere, extending the winter surf zone towards the equator (Haynes and Shuckburgh, 2000a). More rapid horizontal transport and exchange with the extra-tropics occurs in the region $\sim 15-20 \mathrm{~km}(\sim 360-450 \mathrm{~K})$, as evidenced by water vapor (Rosenlof et al., 1997) and other tracers (Santee et al., 2011). Thus, the composition of the tropical lower stratosphere is influenced by both the mean circulation and eddy transport effects.

Observations of the seasonal cycle of ozone in the tropical lower stratosphere show a large annual cycle with a sharply peaked vertical structure, which is in phase with temperature (Randel et al., 2007). Randel et al. (2007) proposed that this behavior results primarily from vertical transport; seasonal variations in the Brewer-Dobson circulation acting on the strong background vertical gradient in ozone can account for the phase, amplitude and vertical structure of the ozone annual cycle. Similar effects occur for other tracers with strong vertical gradients across the tropopause, including carbon monoxide (CO) (Randel et al., 2007) or tropospheric hydrocarbons such as ethane $\left(\mathrm{C}_{2} \mathrm{H}_{6}\right)$ (Park et al., 2013). On the other hand, complementary modeling analyses using a Lagrangian transport framework suggest that the large annual cycle in ozone mainly results from horizontal in-mixing, in particular due to transport associated with the Asian summer monsoon anticyclone (Konopka et al., 2009, 2010; Ploeger et al., 2012). These contrasting viewpoints help to motivate the current analysis.

The recent study of Abalos et al. (2012) analyzed the observed budgets of temperature, ozone and $\mathrm{CO}$ in the tropical lower stratosphere based on the Transformed Eulerian Mean (TEM) formalism, using three derived estimates of tropical upwelling. These results demonstrated the dominant role of tropical mean upwelling in forcing the observed coherent seasonal cycles in temperature and tracers at levels with large background vertical gradients. However, the eddy components of transport could not be estimated by Abalos et al. (2012) because of the coarse resolution of the satellite ozone and CO measurements; their ozone budget calculations include a relatively large residual, which they argue may be associated with unresolved eddy transport. Here we perform a similar detailed budget analysis using the output of a free-running chemistry-climate model (WACCM4), and explicitly evaluate the effects of mean advection, eddy transport and chemical sources/sinks on ozone and CO in the tropical lower stratosphere. We include TEM (on log-pressure vertical coordinates) and isentropic calculations to contrast the results. Because the seasonal cycles in ozone and $\mathrm{CO}$ are strongly correlated with temperature (as a response to variations in upwelling, in turn resulting from variations in wave driving), the variability in tracers is smaller in isentropic coordinates (Konopka et al., 2009), and the two vertical coordinates provide complementary perspectives.

Our analyses first focus on evaluating the behavior of temperature, ozone and $\mathrm{CO}$ in the model simulation, with 
emphasis on the coupled seasonal variations and the associated vertical structure. We then quantify the thermodynamic and tracer budgets in the model, for both the seasonal cycle and sub-seasonal variability.

\section{Model and observational data}

\subsection{WACCM data}

In this study we use six years (2004-2009) of daily data from a free-running simulation with the Whole-Atmosphere Community Climate Model, Version 4 (WACCM4). WACCM4 is the atmospheric component of the coupled climate system model CESM1 (Community Earth System Model, Version 1), extended to cover the altitude range from the surface to the lower thermosphere. It is a fully interactive model, wherein the radiatively active gases $\left(\mathrm{CO}_{2}, \mathrm{H}_{2} \mathrm{O}, \mathrm{N}_{2} \mathrm{O}, \mathrm{CH}_{4}\right.$, $\mathrm{CFCs}, \mathrm{NO}, \mathrm{O}_{3}$ ) influence the radiative heating rates and therefore the dynamics. Processes and parameterizations that are unique to WACCM4 are discussed in Garcia et al. (2007). This simulation uses 66 vertical levels from the ground to $180 \mathrm{~km}$, with a vertical resolution of $1.1-1.4 \mathrm{~km}$ in the upper troposphere-lower stratosphere (UTLS). The horizontal resolution is $1.9^{\circ} \times 2.5^{\circ}$ (latitude $\times$ longitude). The chemical module of WACCM4 is based upon the 3-D chemical transport Model of OZone and Related Tracers, Version 3 (MOZART-3) (Kinnison et al., 2007), incorporating a realistic representation of stratospheric and tropospheric chemistry (in particular, for ozone and CO). The simulation used here is a $50 \mathrm{yr}$ transient run from 1960 to 2010, similar to the REFB1 simulation used in CCMVal-2 (SPARC CCMVal, 2010, Chapter 2). This simulation includes anthropogenic and natural forcings from observations (such as trace gases emissions, quasi-biennial oscillation (QBO) or sea surface temperatures), mostly identical to those used by SPARC CCMVal (2010) for REF-B1.

Tracer transport in WACCM is computed using a finitevolume dynamical core with a Lagrangian control-volume vertical discretization (Lin, 2004). In this technique, the vertical coordinates are material surfaces, which evolve following hydrostatic dynamics. The finite volumes bounded by two neighboring Lagrangian surfaces can therefore float, be compressed or expanded. In particular, the presence of diabatic heating/cooling deforms the surfaces, which must be frequently remapped to hydrostatic pressure coordinates. The remapping process involves vertically redistributing tracer mixing ratios from the Lagrangian control volume to the Eulerian framework. Therefore, the model does not explicitly solve vertical transport and the vertical velocity (omega) is indirectly derived from considering the pressure change implied by the remapping. The possible lack of precise correspondence between the vertical motion implicit in the remapping process and the omega field output by the model (and used in our transport calculations) can lead to small uncertainties in our tracer budgets.

\subsection{Observations}

The temperature, ozone and $\mathrm{CO}$ in the tropical lower stratosphere from the model simulation are compared to observations to demonstrate the ability of the model to represent their spatial structure and variability in a realistic manner. We compare WACCM temperatures with GPS radio occultation observations from the Constellation Observing System for Meteorology Ionosphere and Climate (COSMIC) satellite mission (Anthes et al., 2008). Comparisons are based on COSMIC daily data for the period January 2007 to December 2010 averaged zonally and over tropical latitudes $\left(20^{\circ} \mathrm{S}-\right.$ $20^{\circ} \mathrm{N}$ ). WACCM ozone is compared to tropical ozonesonde measurements from the SHADOZ (Southern Hemisphere ADditional OZonesondes) network (Thompson et al., 2007, 2012), using a subset of 7 near-equatorial stations during the period 1998-2006 (the same data described in Randel et al., 2007). We also use both ozone and CO satellite measurements from the Microwave Limb Sounding (MLS) instrument on the Aura satellite (Livesey et al., 2008). In particular we use daily zonal mean data averaged over $18.75^{\circ} \mathrm{S}-$ $18.75^{\circ} \mathrm{N}$ for the period $2005-2010$. The ozone data have a vertical resolution near $3 \mathrm{~km}$, with data on vertical layers centered on the pressure levels of 100, 83, 68, 56 and $46 \mathrm{hPa} ; \mathrm{CO}$ has a lower vertical resolution of $\sim 4.5 \mathrm{~km}$, with data for levels centered at 100, 68 and $46 \mathrm{hPa}$. Further details of these MLS data can be found in Abalos et al. (2012).

\section{Comparison of WACCM with observations}

\subsection{Tropical UTLS temperature, ozone and CO}

Taguchi (2009) demonstrated that WACCM produces a realistic simulation of the tropical lower stratosphere, including an accurate annual cycle of temperature and circulation. Here we focus more explicitly on comparing the behavior of temperature, ozone and $\mathrm{CO}$ in the model with observations. The vertical structure of tropical mean temperature, ozone and $\mathrm{CO}$, averaged over all the available years, is shown in Fig. 1. The annual mean values agree very well with the observations, and the overall vertical structure is well captured by the model. In particular the model accurately simulates the strong vertical gradients in ozone and $\mathrm{CO}$, which are important features of this region. One relevant difference is that the minimum temperature (i.e. the annual mean cold point tropopause) is found at a higher level in WACCM $(86 \mathrm{hPa})$ compared to GPS observations ( $\sim 95 \mathrm{hPa})$. Note that if GPS temperature data is sampled at the WACCM pressure levels the cold point is located at $101 \mathrm{hPa}$, one level below the cold point in the model results. 


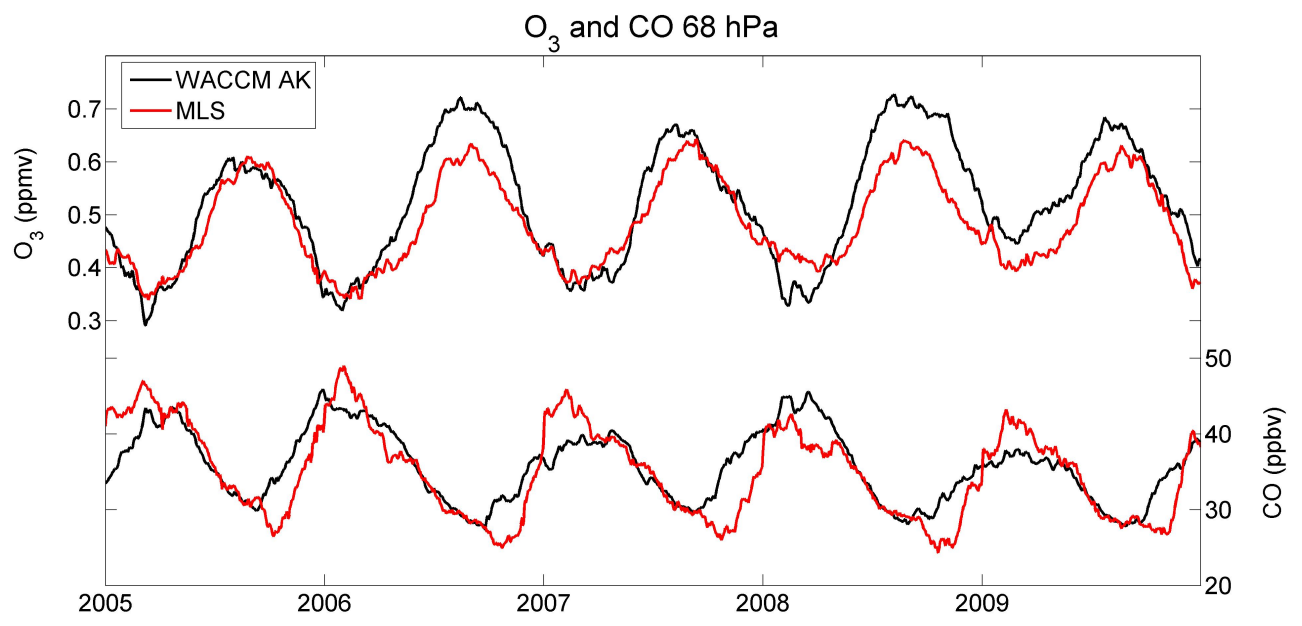

Fig. 2. Time series of zonal mean $68 \mathrm{hPa}$ ozone and CO from MLS observations (red lines) and from WACCM (calculated using MLS averaging kernels, black lines). Results are averaged over $18^{\circ} \mathrm{S}-18^{\circ} \mathrm{N}$ for WACCM and $18.75^{\circ} \mathrm{S}-18.75^{\circ} \mathrm{N}$ for MLS.

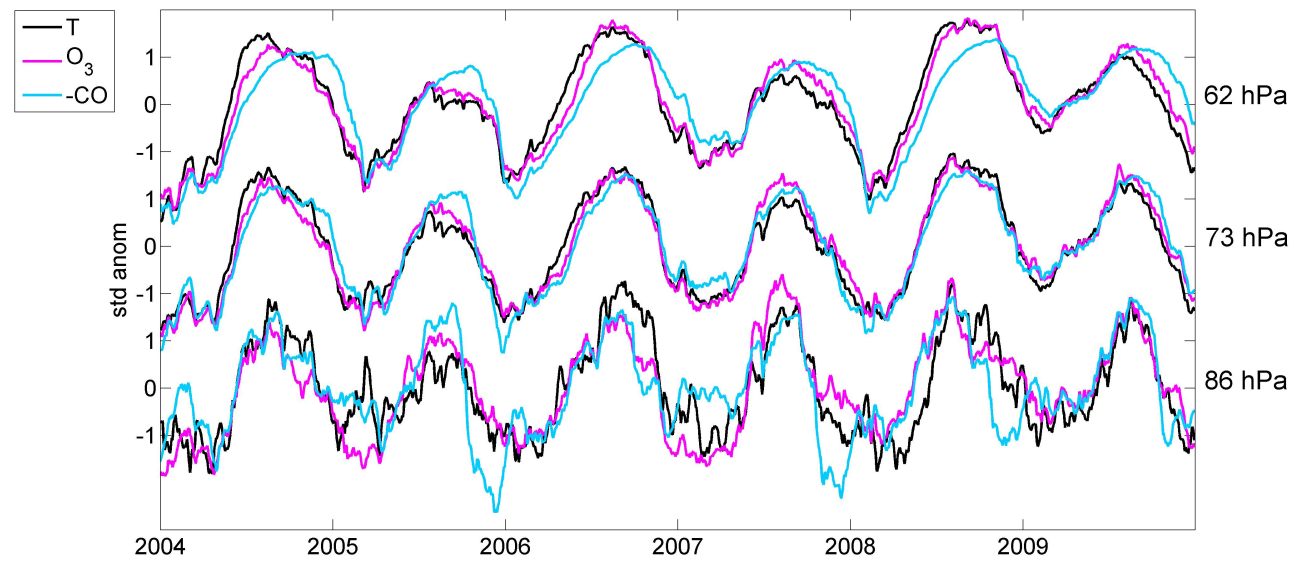

Fig. 3. Time series of zonal mean temperature, ozone and CO from WACCM at 62,73 and $86 \mathrm{hPa}$ averaged over $18^{\circ} \mathrm{S}-18^{\circ} \mathrm{N}$. Standardized anomalies are shown for each level, and the anomalies of $\mathrm{CO}$ are inverted to highlight correlated behavior.

Time series of ozone and CO from WACCM are compared to five years of MLS observations at $68 \mathrm{hPa}$ (first level above the tropopause where both ozone and CO MLS observations are available) in Fig. 2, with MLS averaging kernels applied to the model results. These time series show the key feature of large annual cycles in ozone and $\mathrm{CO}$, which are approximately out of phase. There is good agreement in the magnitude and phase of the seasonal cycles between the model and the observations for both tracers. Abalos et al. (2012) highlighted the correlated variability between temperature, ozone and $\mathrm{CO}$ across the tropical tropopause from observations. Similar coherent behavior is seen in WACCM, both for the seasonal cycles and the sub-seasonal variability (i.e., timescales shorter than the seasonal cycle), as shown in Fig. 3 (compare to Fig. 1 in Abalos et al., 2012). Note that the model realistically produces a semi-annual cycle in $\mathrm{CO}$ concentrations near the tropopause $(86 \mathrm{hPa})$, linked to surface emissions (see Abalos et al., 2012).
Randel et al. (2007) pointed out that the annual cycles in temperature, ozone and $\mathrm{CO}$ are characterized by a sharply peaked vertical structure above the tropical tropopause. Figure 4 shows that this important feature is reproduced in WACCM with realistic amplitudes, although the relative maxima are shifted to slightly higher altitudes in the model compared to observations for temperature and ozone. The lower resolution of the $\mathrm{CO}$ measurements does not allow a similar detailed comparison (note that $\mathrm{CO}$ model results weighted with MLS averaging kernels are also shown in Fig. 4). This vertical shift may be related to the higher altitude of the cold point in WACCM compared to observations (Fig. 1a). Despite this difference, WACCM is able to reproduce the characteristic vertical structure of the seasonal cycles; however one should be aware that, in terms of temperature structure and tracer variability near the tropical tropopause, a given vertical level in the model does not correspond exactly to the same level in the observations. 

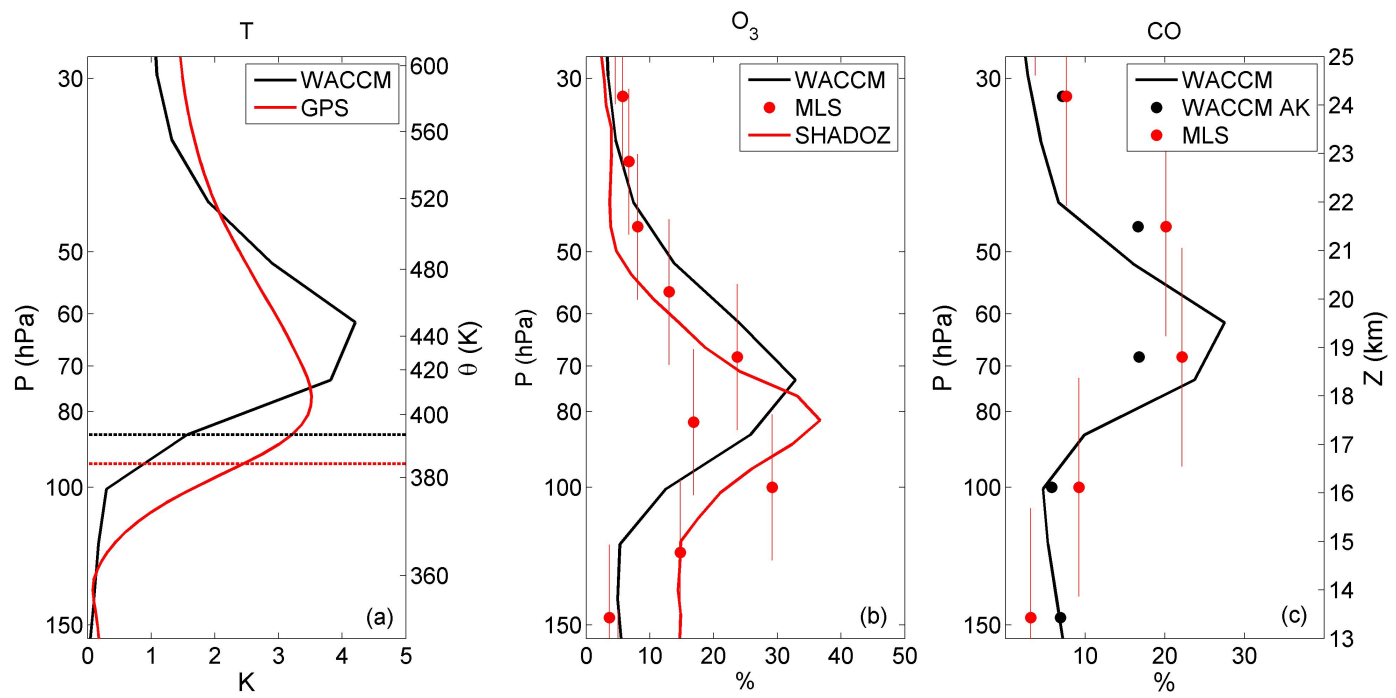

Fig. 4. As in Fig. 1 but for the vertical structure of annual cycle amplitude in temperature (a), ozone (b) and CO (c) in the tropics. The amplitude for the tracers is shown relative to the annual mean concentration.
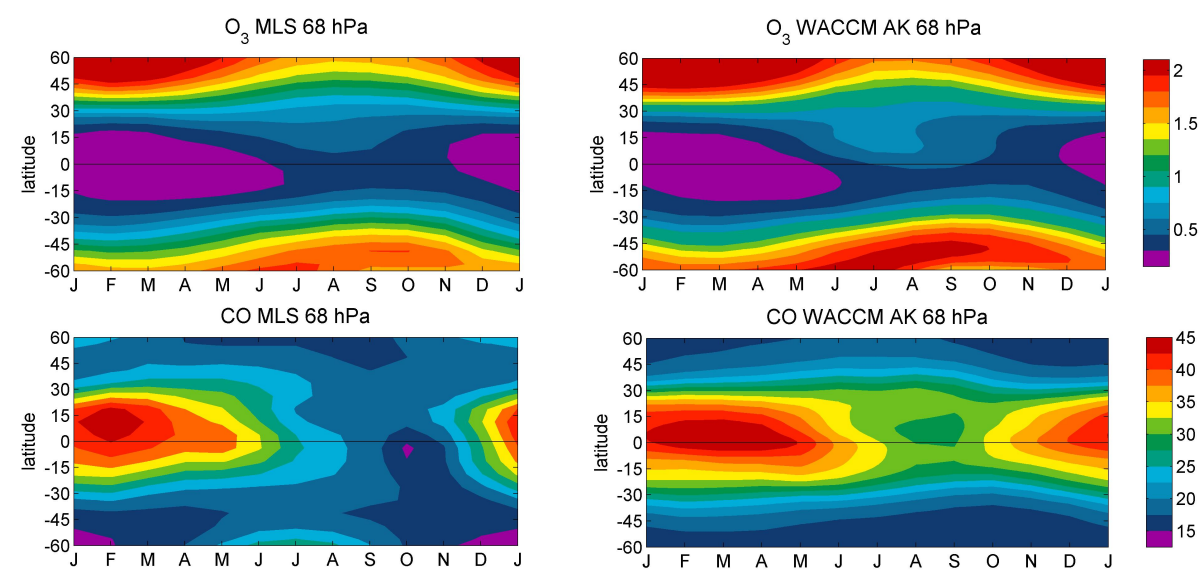

Fig. 5. Mean seasonal cycles of ozone (ppmv, upper panels) and CO (ppbv, lower panels) in MLS (left) and WACCM (right) at $68 \mathrm{hPa}$. MLS averaging kernels have been applied to WACCM data.

Note that the MLS ozone annual amplitude agrees reasonably well with the ozonesonde measurements, except at the $83 \mathrm{hPa}$ level, where the MLS value is too small.

Figure 5 shows the latitudinal structure of the seasonal variation in ozone and $\mathrm{CO}$ at $68 \mathrm{hPa}$ in WACCM (with MLS averaging kernels applied) and in MLS. There is good agreement between the model and the observations, and WACCM realistically represents the latitudinal swing of the tropical concentrations towards the summer hemisphere and the meridional gradients, stronger during winter in each hemisphere for both tracers. There is an asymmetry between the hemispheres in the ozone seasonality, with higher ozone concentrations during $\mathrm{NH}$ summer in the northern part of the tropics compared to the southern part, which is more pronounced in the model than in the observations. For $\mathrm{CO}$, WACCM slightly overestimates the latitudinal gradients compared with MLS observations and does not show the deep minimum in October-November in the SH tropics seen in MLS, but the overall structure is quite realistic.

In general, WACCM reproduces the key spatial features and temporal variability in temperature, ozone and $\mathrm{CO}$ and hence we conclude that the model is a useful tool for the analysis of tracer transport in the tropical UTLS.

\subsection{Thermodynamic balance}

As a background to understanding the seasonality in the tracer budgets, we include the analysis of the model thermodynamic balance in the tropics, based on the TEM formalism (Andrews et al., 1987): 

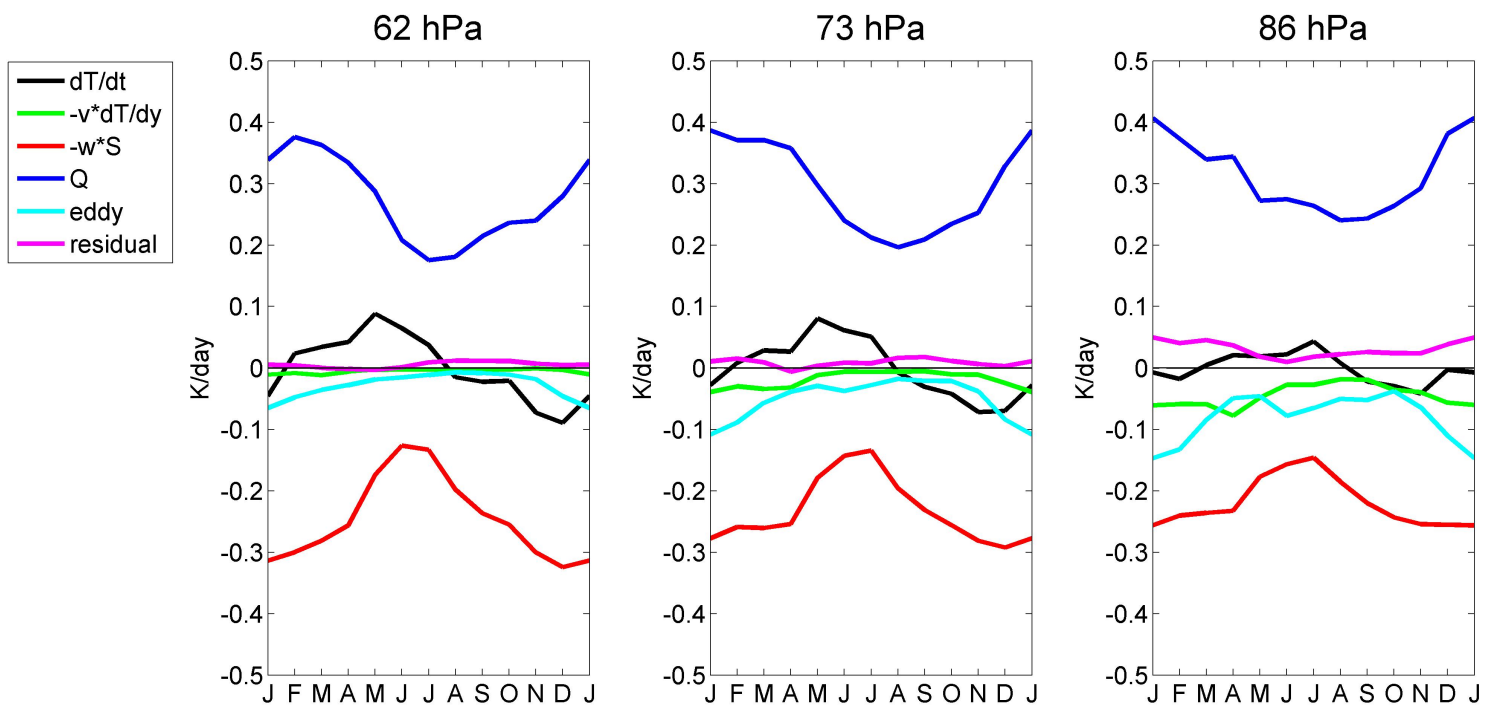

Fig. 6. Mean seasonal cycle (monthly means) of all the terms in the thermodynamic balance (Eq. 1) in WACCM computed at three pressure levels and averaged over $18^{\circ} \mathrm{S}-18^{\circ} \mathrm{N}$.

$$
\begin{aligned}
& \bar{T}_{\mathrm{t}}=-\bar{v}^{*} \bar{T}_{y}-\bar{w}^{*} S+\bar{Q} \\
& -e^{z / H}\left[e^{-z / H}\left(\overline{v^{\prime} T^{\prime}} \frac{\bar{T}_{y}}{S}+\overline{w^{\prime} T^{\prime}}\right)\right]_{z} .
\end{aligned}
$$

In this equation and in the rest of the manuscript overbars indicate zonal means, primes are deviations from it, and subscripts denote partial derivatives. $\bar{Q}$ is the diabatic heating, $\left(\bar{v}^{*}, \bar{w}^{*}\right)$ are the components of the residual circulation, $S=H \cdot N^{2} / R$ with $H=7 \mathrm{~km}, R=287 \mathrm{~m}^{2} \mathrm{~s}^{-2} \mathrm{~K}^{-1}$ and $N^{2}$ is the Brunt-Väisälä frequency. Figure 6 shows the monthly mean budget terms in Eq. (1), evaluated at model levels 86,73 and $62 \mathrm{hPa}$ averaged over $18^{\circ} \mathrm{S}-18^{\circ} \mathrm{N}$. The last term on the right-hand side of Eq. (1) is labeled "eddy" in Fig. 6, and there is a small residual term, which is the difference between the actual tendency $\left(\bar{T}_{\mathrm{t}}\right)$ and that computed from Eq. (1) (this definition of residual is valid elsewhere in the manuscript). The thermodynamic balance in the tropical lower stratosphere is primarily between cooling by mean upwelling $\left(-\bar{w}^{*} S\right)$ and radiative heating $(\bar{Q})$, and these show annual cycles which follow the stronger upwelling during boreal winter. The temperature tendency closely mimics the upwelling. The WACCM thermodynamic balance is similar to quasi-observational estimates based on ERA-Interim reanalysis data by Abalos et al. (2012). At the cold point tropopause level $(86 \mathrm{hPa})$, the eddy term in Eq. (1) is a fairly large term in the balance. This eddy term is mainly associated with the vertical eddy heat flux, $\overline{w^{\prime} T^{\prime}}$, which is relatively important only over a narrow vertical layer just around the tropical tropopause. This result from the model shows similar magnitude and seasonality as the ERA-Interim calculation in Abalos et al. (2012). Figure 6 shows that the mechanisms that lead to the large seasonal cycle in WACCM temperature in this region are consistent with the observations, linked primarily to the seasonal cycle in upwelling. This is an important test for the model, and indicates a realistic simulation of dynamical and thermal processes in the tropical lower stratosphere.

\section{Tracer transport}

\subsection{Time average tracer budgets}

The TEM continuity equation for zonal mean tracer concentration gives the local change in tracer concentration as a result of transport processes and chemical sources and sinks (Andrews et al., 1987, Eq. 9.4.13):

$\bar{\chi}_{t}=-\bar{v}^{*} \bar{\chi}_{y}-\bar{w}^{*} \bar{\chi}_{z}+e^{z / H} \nabla \cdot \boldsymbol{M}+P-L$,

In this equation, transport of the zonal mean tracer concentration $(\bar{\chi})$ occurs via advection by the residual circulation $\left(\bar{v}^{*}, \bar{w}^{*}\right)$ and eddy effects $\left(e^{z / H} \nabla \cdot \boldsymbol{M}\right)$, and $P-L$ is the chemical production minus loss rate. The eddy transport term is formulated as the divergence of the eddy transport vector, $\boldsymbol{M}$, with components defined as in Eq. 9A.3 of Andrews et al. (1987):

$$
\left\{\begin{array}{l}
M_{y}=-e^{-z / H}\left(\overline{v^{\prime} \chi^{\prime}}-\frac{\overline{v^{\prime} T^{\prime}}}{S} \bar{\chi}_{z}\right) \\
M_{z}=-e^{-z / H}\left(\overline{w^{\prime} \chi^{\prime}}+\frac{\overline{v^{\prime} T^{\prime}}}{S} \bar{\chi}_{y}\right)
\end{array}\right.
$$

Figure 7 illustrates the effects of residual mean advection and eddy transport on ozone and CO concentrations in the annual mean. Given the sharp vertical gradients in this region, it is convenient to represent changes in ozone and $\mathrm{CO}$ relative to 

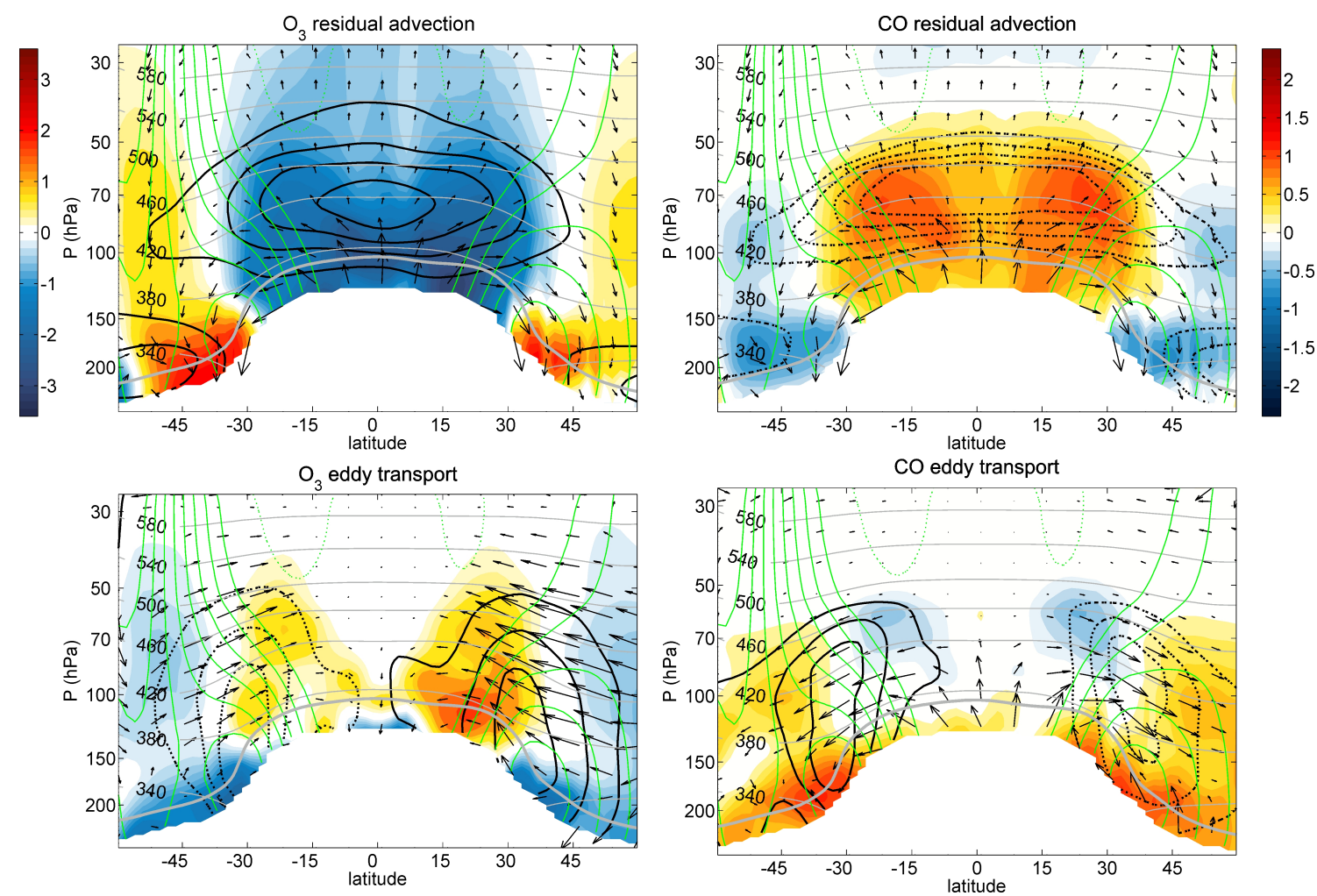

Fig. 7. Annual mean of residual advection (upper panels) and eddy transport (lower panels) for ozone (left) and CO (right) in WACCM, formulated in local percentage tendencies, as in Eq. (4). In upper panels, shading: $-\bar{v}^{*} \ln (\bar{\chi})_{y}-\bar{w}^{*} \ln (\bar{\chi})_{z}$, arrows: $\left(\bar{v}^{*}, \bar{w}^{*}\right)$, black contours: vertical tracer gradient (dashed: negative, solid: positive). In lower panels, shading: $e^{z / H} \nabla \cdot \boldsymbol{M} / \bar{\chi}$, arrows: $\left(-M_{y},-M_{z}\right)$, black contours: meridional tracer gradient. Units of tracer tendency (shading) are $\left(\%\right.$ day $\left.^{-1}\right)$ with respect to the annual mean concentration. Green contours show annual mean zonal wind (contour spacing: $5 \mathrm{~m} \mathrm{~s}^{-1}$ ). A few annual mean isentropes are shown in gray and labeled. The annual mean lapse rate tropopause is indicated by the thick gray line.

the time mean concentration at each location; thus, the terms in Fig. 7 are expressed as local percentage values. This is equivalent to re-writing Eq. (2) in terms of the logarithm of tracer concentration:

$$
\begin{aligned}
\ln (\bar{\chi})_{t} & =-\bar{v}^{*} \ln (\bar{\chi})_{y}-\bar{w}^{*} \ln (\bar{\chi})_{z}+e^{z / H} \nabla \cdot \boldsymbol{M} / \bar{\chi} \\
& +(P-L) / \bar{\chi}
\end{aligned}
$$

and representing the time-mean of this equation. The arrows in Fig. 7 illustrate the components of the mean residual circulation $\left(\bar{v}^{*}, \bar{w}^{*}\right)$ in the upper panels (corresponding to advective transport), and the components of the vector $\boldsymbol{M}$ with the sign reversed $\left(-M_{y},-M_{z}\right)$ in the lower panels (corresponding to eddy transport). Figure 7 shows that, for both tracers, transport in the tropical lower stratosphere is dominated by the advective component, which is mainly due to vertical advection by tropical upwelling (plus a smaller contribution from meridional advection by the shallow branch of the residual circulation below $\sim 70 \mathrm{hPa}$ ). The eddy component of transport occurs mostly along isentropes in the sub-tropics and middle latitudes. Advection by the residual circulation leads to decrease in ozone (increase in $\mathrm{CO}$ ) concentrations in the tropics and increase (decrease) in the extra-tropics, and tracer tendencies are largest where the background vertical gradients are enhanced (indicated by the black contours). On the other hand, eddy transport acts to increase ozone (decrease $\mathrm{CO}$ ) concentrations on the equatorward upper flanks of the subtropical jets, and decrease ozone (increase $\mathrm{CO}$ ) in the extra-tropics. The largest eddy transport coincides with the regions of large meridional gradients (black contours), near the upper flanks of the subtropical jets.

\subsection{Seasonal cycles}

While the previous section focused on separating mean advection and eddy transport effects, we use a slightly different analysis in the rest of the work, based on separating the vertical and horizontal components of tracer transport. This simplifies the interpretation of the results and is motivated by the fact that, in the tropical lower stratosphere, mean advection is mainly vertical and eddy transport effects are mainly horizontal (cf. Fig. 7). To separate vertical and horizontal transport we simply rearrange Eq. (2): 

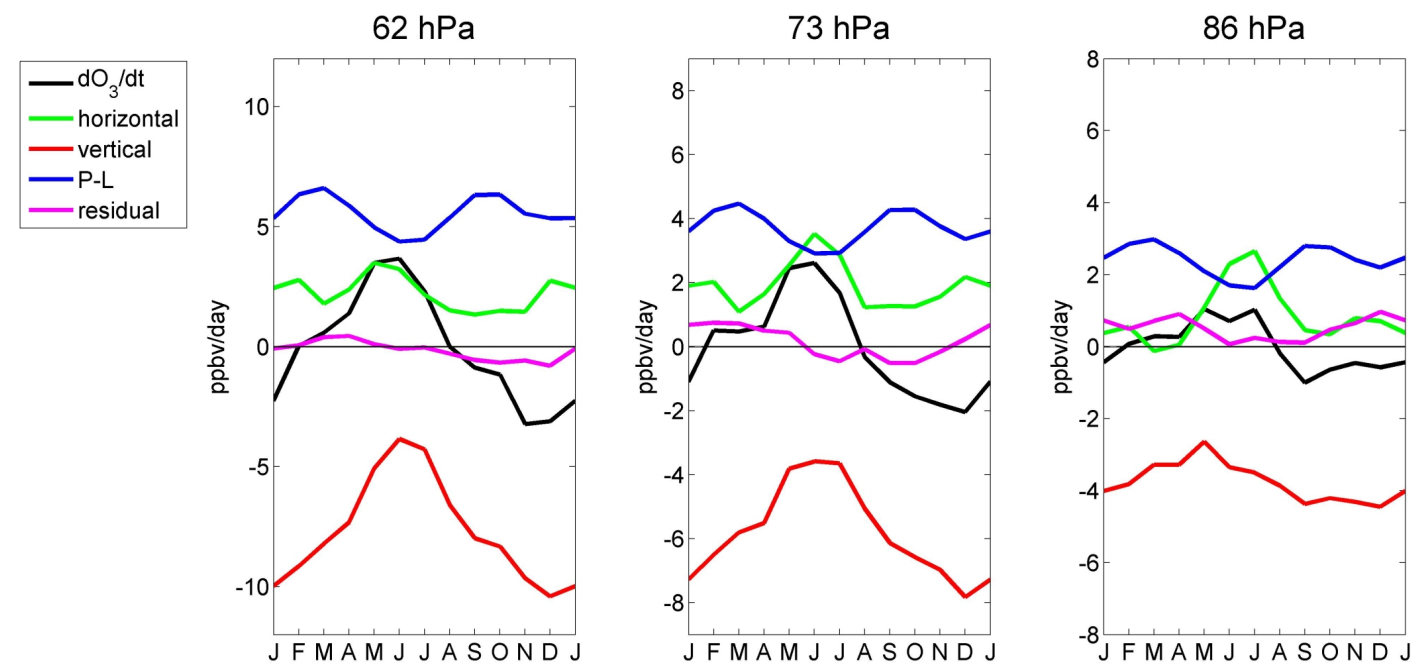

(a)
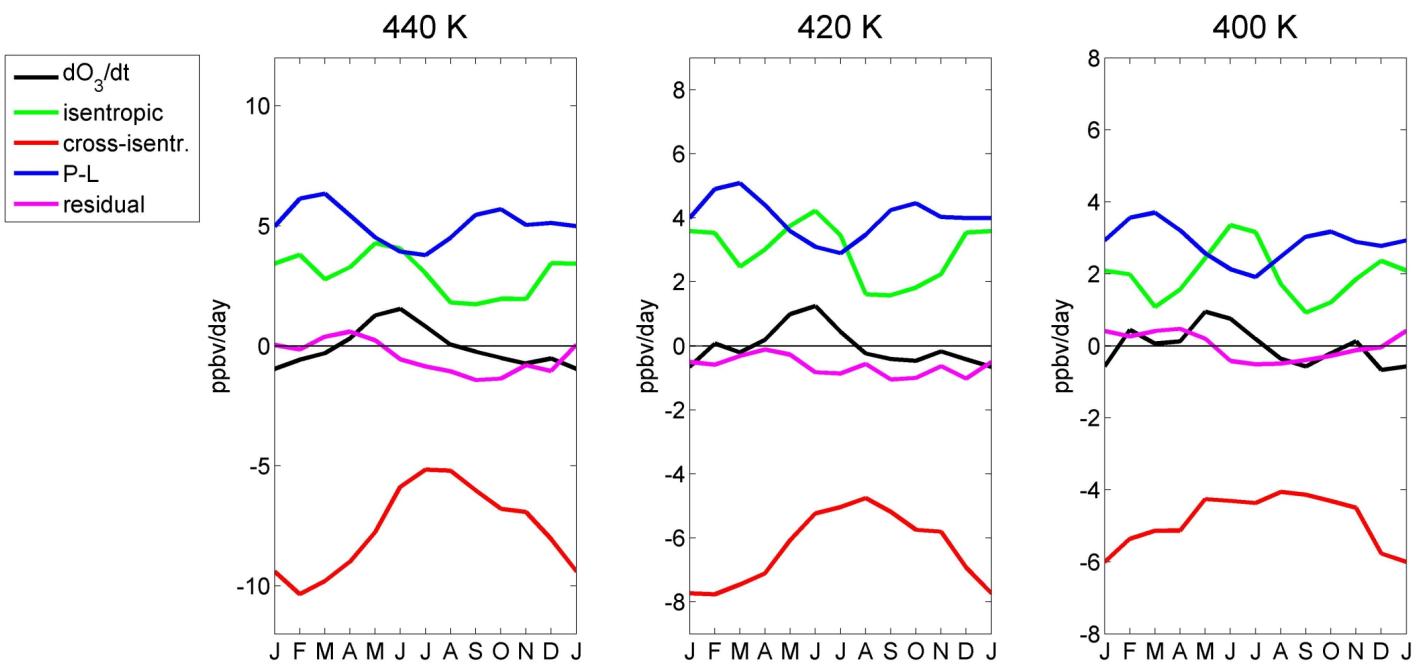

(b)

Fig. 8. Mean seasonal cycles (monthly means) of terms in the ozone continuity equation averaged over $18^{\circ} \mathrm{S}-18^{\circ} \mathrm{N}$ on pressure levels (Eq. 5 , a) and isentropic levels (Eq. 6, b).

$$
\begin{array}{r}
\bar{\chi}_{\mathrm{t}}=\left[-\bar{v}^{*} \bar{\chi}_{y}+e^{z / H}(\cos \varphi)^{-1}\left(M_{y} \cos \varphi\right)_{y}\right] \\
+\left[-\bar{w}^{*} \bar{\chi}_{z}+e^{z / H}\left(M_{z}\right)_{z}\right]+P-L .
\end{array}
$$

The complete ozone and CO budgets showing all advective and eddy transport terms separately can be found in the Appendix (Figs. A1 and A2).

The use of isentropic coordinates is common in tracer transport studies, since for negligible diabatic heating rates tracers tend to move on constant potential temperature surfaces. Although this is not the case in the tropical lower stratosphere, where diabatic heating is a dominant term (see Fig. 6), it is enlightening to complement our analyses with analogous calculations on isentropes. In this coordinate system the continuity equation for the tracers is (Eq. 9.4.21 of Andrews et al., 1987):

$$
\begin{array}{r}
\bar{\chi}_{\mathrm{t}}=\left\{-\bar{v}^{*} \bar{\chi}_{y}-\bar{\sigma}^{-1}\left[\overline{(\sigma v)^{\prime} \chi^{\prime}}\right]_{y}\right\} \\
+\left\{-\bar{Q}^{*} \bar{\chi}_{\theta}-\bar{\sigma}^{-1}\left[\overline{(\sigma Q)^{\prime} \chi^{\prime}}\right]_{\theta}\right\}+\bar{P}^{*}-\bar{L}^{*}
\end{array}
$$

where the variables with a star:

$\bar{A}^{*} \equiv \frac{(\overline{\sigma A})}{\bar{\sigma}}$

represent mass-weighted variables, defining the "density" on isentropes as

$\sigma \equiv-\frac{1}{g} \frac{\partial p}{\partial \theta}$.

Note that we have omitted the transient term: $-\bar{\sigma}^{-1}\left(\overline{\sigma^{\prime} \chi^{\prime}}\right)_{t}$ in Eq. (6), which is negligible for ozone and $\mathrm{CO}$ budgets in our region of interest (not shown). 


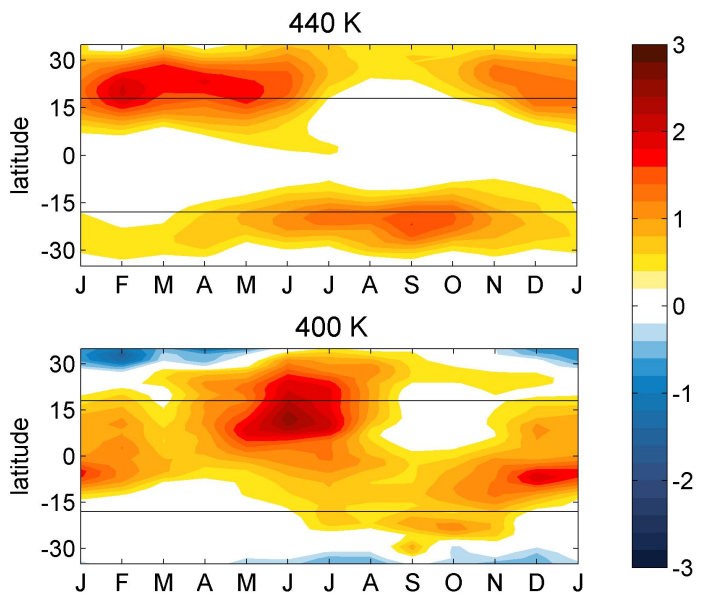

Fig. 9. Mean seasonal cycle (monthly means) of ozone relative tendency due to isentropic transport at $440 \mathrm{~K}$ and $400 \mathrm{~K}$ as a function of latitude. Tendencies are divided by the local annual mean concentration. Horizontal black lines indicate the location of $18^{\circ} \mathrm{S}$ and $18^{\circ} \mathrm{N}$ latitudes. Units: $\left(\%\right.$ day $\left.^{-1}\right)$.

Figure 8a shows the terms in the WACCM ozone budget (Eq. 5) on the same pressure levels shown in Fig. 6. There is a large seasonal cycle in ozone at the upper level $(62 \mathrm{hPa})$, which follows closely the seasonality in vertical transport (mainly tied to advection by tropical upwelling, see Fig. A1). There is a small semi-annual cycle in the chemical net production rates, linked to the sun transit over the equator in the equinox seasons. Note that the horizontal transport is a relatively small positive term and shows little seasonal variation at this level. There is also a small near-constant residual in these calculations, which might be related to uncertainties in the numerical calculations. At lower levels the amplitude of the ozone annual cycle decreases, as does the seasonality in the vertical transport term. On the other hand, at the lowest level ( $86 \mathrm{hPa}$, near the model tropopause) the seasonality in the horizontal transport term shows a maximum during $\mathrm{NH}$ summer, which approximately coincides with the positive ozone tendency. Figure A1 shows that horizontal eddy transport makes the largest contribution to this summer maximum at tropopause level. Overall, the balances in Fig. 8a are consistent with the observationally derived ozone balances in Abalos et al. (2012), especially taking into account the differences in vertical levels discussed above. The WACCM results support their hypothesis that the residual in the observational calculations is mainly associated with eddy transport effects.

Figure $8 \mathrm{~b}$ shows the terms in the ozone continuity equation on isentropic levels (Eq. 6), combining isentropic (quasihorizontal) and cross-isentropic (quasi-vertical) terms, as in the analysis on pressure levels. Overall, the ozone budgets are similar in pressure (Fig. 8a) and isentropic (Fig. 8b) coordinates, and in particular the cross-isentropic transport is a dominant term in the budget at each level. However, on isentropic coordinates the amplitude of the annual cycle in

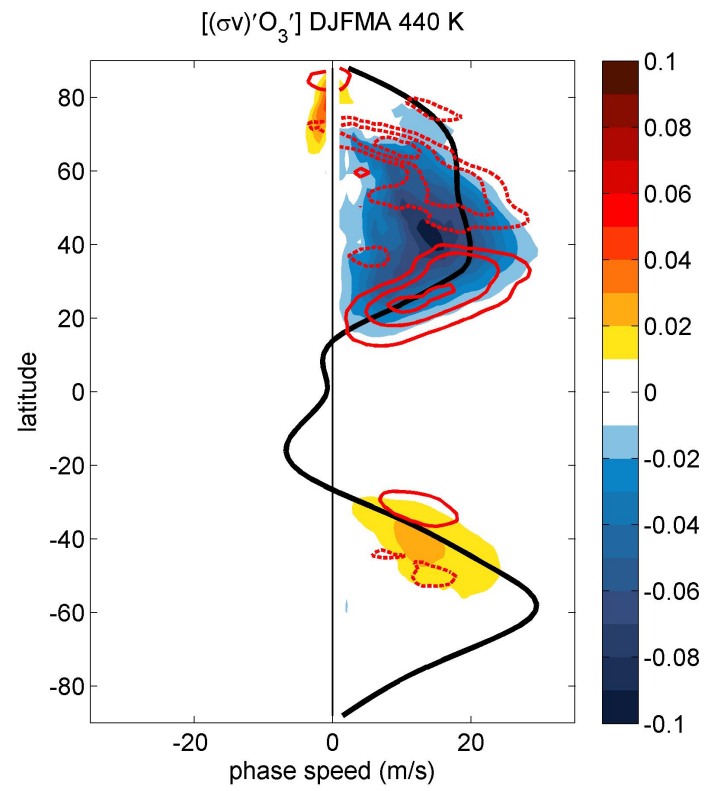

Fig. 10. Latitude versus phase-speed representation of the ozone eddy flux co-spectrum at $440 \mathrm{~K}$ for the winter-spring season (December through April). The spectrum of the eddy covariance $\left(\overline{(\sigma v)^{\prime} \mathrm{O}_{3}{ }^{\prime}}\right)$ is multiplied by the cosine of latitude to emphasize the behavior in low latitudes. Red contours represent the meridional convergence of the eddy flux (term $-\bar{\sigma}^{-1}\left[\overline{(\sigma v)^{\prime} \mathrm{O}_{3}^{\prime}}\right]_{y}$ in Eq. 6); solid contours indicate convergence of the eddy flux, associated with positive ozone tendencies. The solid black line shows the zonal mean zonal wind. A 9-point running mean in-phase speed is applied to the contours. (Shading units: $\mathrm{kg} \mathrm{m}^{-1} \mathrm{~s}^{-1} \mathrm{~K}^{-1} \mathrm{ppmv}$, contour levels spacing is $0.2 \mathrm{ppbv}^{-1} \mathrm{day}^{-1}$ ).

ozone is largely reduced, so that the ozone tendency is relatively small at every level compared to the other terms in the balance. This decrease in seasonal cycle amplitude is due to the annual cycle in potential temperature, which is almost in phase with ozone, as previously pointed out by Konopka et al. (2009). The relative amplitude of the annual cycle in ozone is reduced by $>50 \%$ on isentropes compared to the amplitude on pressure levels, and its vertical structure changes as well: the relative maximum amplitude on isentropic coordinates is found at lower levels, close to the tropopause ( 380-400 K) (result not shown). The isentropic transport (mainly due to the eddies, see Fig. A1) is similar to the horizontal transport observed on pressure levels, showing a boreal summer maximum near the tropopause (e.g. $400 \mathrm{~K}$ ) and less seasonality at higher levels.

The change in the seasonality of isentropic transport with height is shown more clearly in the latitude-month sections in Fig. 9; the results are very similar for horizontal transport on nearby pressure levels. At the upper levels (e.g. $440 \mathrm{~K}$ ) maximum tendencies occur in the sub-tropics during winter and spring in each hemisphere (larger in the NH). This is mainly due to enhanced isentropic eddy transport just 


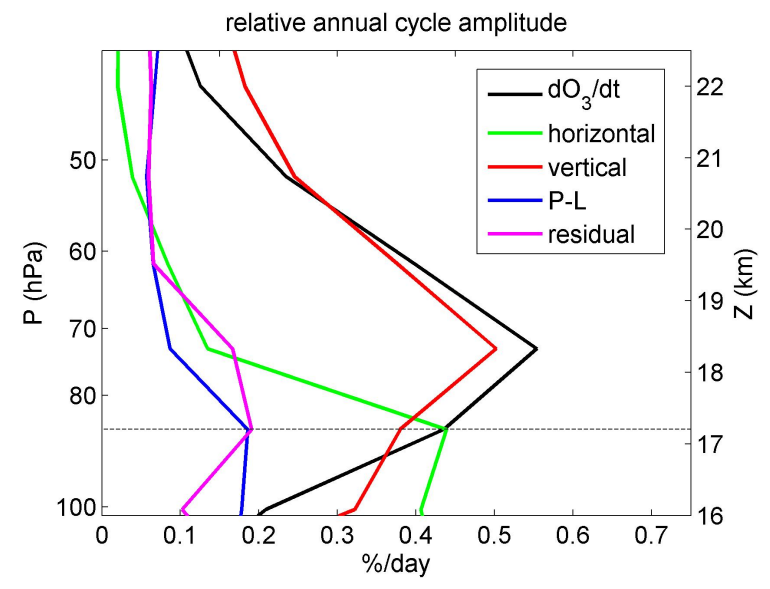

Fig. 11. Vertical structure of the annual cycle amplitude of the terms in the TEM continuity equation for ozone concentration (Eq. 5) averaged over $18^{\circ} \mathrm{S}-18^{\circ} \mathrm{N}$. Relative amplitudes are obtained dividing by the annual mean concentration. The approximate altitude is calculated as for Fig. 1. The dashed horizontal line indicates the location of the annual mean cold point tropopause in WACCM.

above the sub-tropical jets during these seasons, acting on the strong background meridional gradients in ozone (see Fig. 7). This eddy transport is further characterized in Fig. 10, which shows the ozone eddy flux $\left(\overline{(\sigma v)^{\prime} \mathrm{O}_{3}{ }^{\prime}}\right)$ at $440 \mathrm{~K}$ for northern winter and spring (DJFMA) as a function of latitude and phase speed of the eddies. This is calculated based on the space-time co-spectrum of the ozone eddy fluxes, interpolated from frequency to phase-speed space following Randel and Held (1991). The results show a broad region of negative (i.e. equatorward) ozone eddy flux in the $\mathrm{NH}$ associated with eastward traveling (Rossby) waves, and there is convergence of the eddy flux in the sub-tropics (term $-\bar{\sigma}^{-1}\left[\overline{(\sigma v)^{\prime} \mathrm{O}_{3}^{\prime}}\right]_{y}$ in Eq. 6), associated with the positive ozone tendencies seen in Fig. 9 (upper panel). This flux convergence in the subtropics is mainly due to medium-scale eddies with wavenumbers between $\sim 4-10$ (not shown) and phase speeds of $\sim 5-$ $20 \mathrm{~m} \mathrm{~s}^{-1}$. It is interesting to note that the patterns of subtropical eddy flux convergence approximately follow the zonal mean winds $(\bar{u})$ at this level, which is suggestive of critical layer interactions (where the wave phase speed $c$ is close to $\bar{u}$ ). This behavior is consistent with eddy flux convergences associated with Rossby wave breaking near critical levels as discussed, for example, in Homeyer and Bowman (2013).

At levels closer to the tropopause (such as $400 \mathrm{~K}$ ) the amplitude of the ozone winter eddies is much smaller, and isentropic (eddy) transport shows a single maximum during NH summer (Fig. 9, lower panel). This enhanced summer horizontal transport of ozone into the tropics is linked to the anticyclonic circulation associated to the Asian (and North American) monsoons, which carry middle-latitude air masses with high ozone concentrations into the tropics (WACCM ozone and horizontal wind climatology for boreal summer is qualitatively similar to Fig. 7 in Konopka et al., 2010). This result is consistent with the works of Konopka et al. (2010) and Ploeger et al. (2012). The present WACCM calculations (e.g. Fig. 9) highlight the finding that the summer monsoon maximum in horizontal transport is primarily a feature found close to the tropopause, while very different seasonal behavior is observed at higher altitudes. This change with altitude in the seasonality of the ozone transport terms is evidenced in Fig. 11, which shows the vertical structure of the relative annual amplitude of each term in the TEM budget. The sharp peak in the seasonality of the ozone tendency in the lower stratosphere (around $\sim 70 \mathrm{hPa}$ ) is clearly associated with that in vertical transport (thus in tropical upwelling), while the seasonality in horizontal transport is important at lower levels, near the tropopause. Note that although Fig. 11 shows the amplitude but not the phasing of the annual cycles, Fig. 8a shows clear in-phase behavior between the observed ozone tendency and the largest forcing at each level. We also note that the vertical shift in the tropopause height and the maximum ozone amplitude in WACCM as compared to observations (Fig. 4b) can influence the structure in Fig. 11. In particular, it is not trivial to guess how the different transport terms would change if these biases were removed from the model.

Figure 12 shows the balance of the terms in the $\mathrm{CO}$ continuity equation in WACCM. The primary balance is between the increase due to mean upwelling and decrease by photochemical loss, and there is a strong annual cycle in the $\mathrm{CO}$ tendency (at 62 and $73 \mathrm{hPa}$ ) that follows the upwelling. For CO the horizontal transport is relatively smaller than for ozone, and this is due to the smaller background meridional gradients in CO (as noted by Ploeger et al., 2012). At levels close to the tropopause $(86 \mathrm{hPa})$ a semi-annual cycle in $\mathrm{CO}$ is evident, linked to variations in $\mathrm{CO}$ sources and nearequatorial deep convection (e.g. Liu et al., 2013; Park et al., 2013). In isentropic coordinates the annual cycle amplitude of $\mathrm{CO}$ is reduced by $\sim 30 \%$ with respect to that on pressure levels, but the vertical structure is not significantly changed in this case (not shown). The cross-isentropic (quasi-vertical) transport term is the largest term in the isentropic balance, with a seasonal cycle that is delayed $\sim 1-2$ months compared to the cycle in pressure coordinates.

\subsection{Sub-seasonal variability}

The time series of WACCM temperature and tracers in Fig. 3 show correlated variability at timescales shorter than the seasonal cycle. Similar coherent sub-seasonal variability is seen in observations, and Abalos et al. (2012) showed that these were linked to transient variations in tropical upwelling. Using WACCM output we are able to evaluate the contribution from all the transport terms to the sub-seasonal variability in the tracers. We do this by first filtering the time series to isolate sub-seasonal variations (retaining periods $<1 \mathrm{yr}$ ), and then examining correlations among the different terms in the 

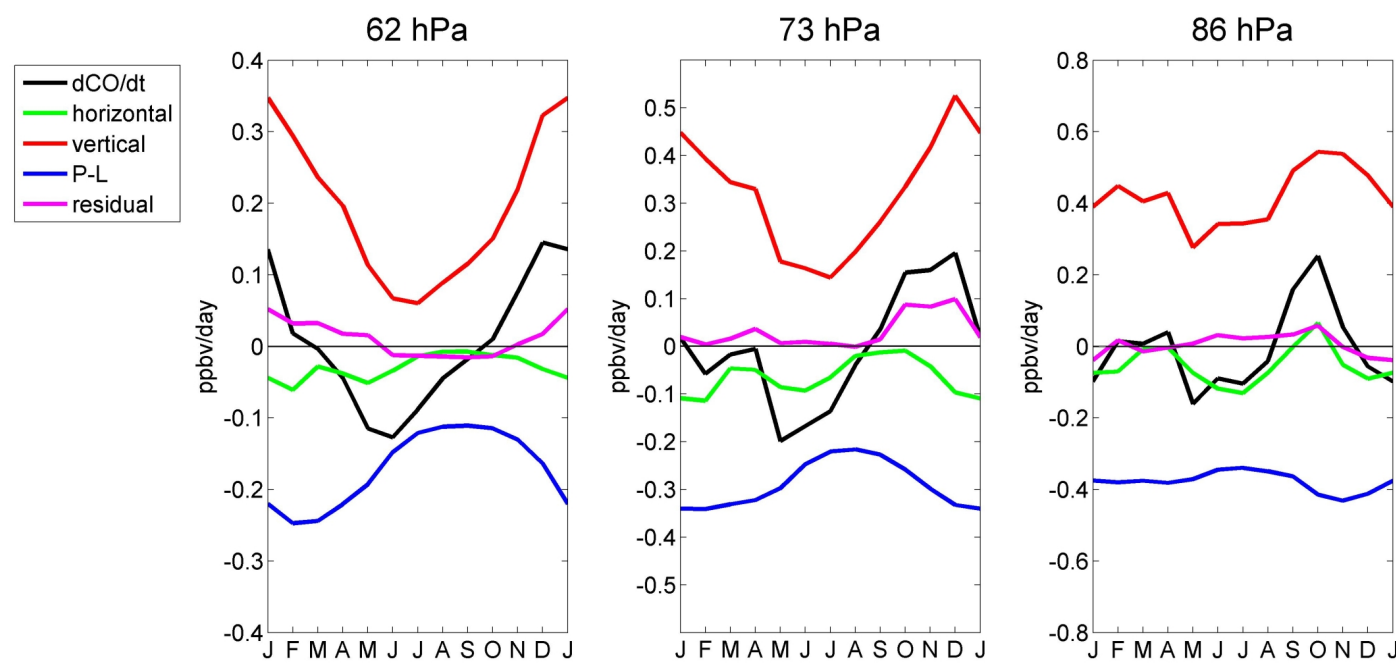

(a)
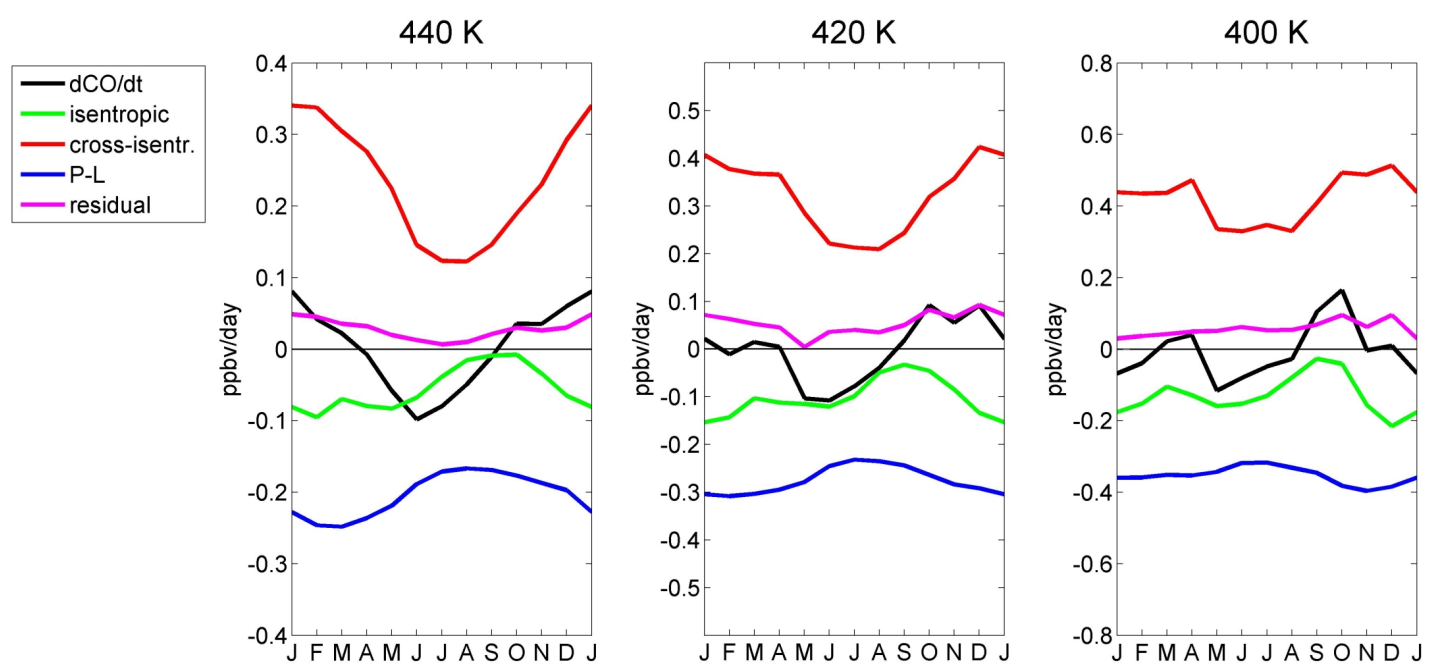

(b)

Fig. 12. Mean seasonal cycle (monthly means) of the terms in the CO continuity equation averaged over $18^{\circ} \mathrm{S}-18^{\circ} \mathrm{N}$ on pressure levels (Eq. 5, a) and isentropic levels (Eq. 6, b).

thermodynamic and tracer continuity equations (Eqs. 1 and 5 respectively). Figure 13a shows the correlation between temperature tendency $(\partial \bar{T} / \partial t)$ and vertical advection by tropical upwelling, revealing high correlations $(\sim 0.8)$ at and above $73 \mathrm{hPa}$. At lower levels, near and below the tropopause $(86 \mathrm{hPa})$, the correlations of $\partial \bar{T} / \partial t$ with upwelling decrease and diabatic heating $(\bar{Q})$ gradually becomes the main driver of sub-seasonal variability in temperature. Figure $13 \mathrm{~b}$ and $\mathrm{c}$ show the correlations of the ozone and $\mathrm{CO}$ tendencies with vertical and horizontal transport terms. In both cases subseasonal tracer fluctuations are most strongly correlated with the vertical transport. There is also a contribution from horizontal transport, particularly at lower levels, which is somewhat more important for ozone than for CO. Tropical upwelling and the eddy term make the primary contributions to the vertical transport and the horizontal transport, respectively, and the correlations of the tracer tendencies with these components are also shown in Fig. 13b and c. Note that for $\mathrm{CO}$ at lower levels a large fraction of the correlations with vertical transport are not explained by upwelling, because of an important contribution from vertical eddy transport. This vertical eddy transport in the model is linked to regional positive $\mathrm{CO}$ anomalies (originating from localized emissions), which coincide with enhanced vertical velocity anomalies.

As with the seasonal cycle, the variability of tracers on sub-seasonal timescales is reduced in isentropic compared to log-pressure coordinates, because transient upwelling forces correlated variations in temperature and tracers. The fraction of sub-seasonal variability on isentropes compared to that on nearby pressure levels decreases from $\sim 75 \%$ near $86 \mathrm{hPa}$ to $\sim 30 \%$ near $62 \mathrm{hPa}$ for ozone and $\mathrm{CO}$. The vertical structure is the mirror image of the correlations between each of the tracers and temperature, i.e., the fraction is low where the tracer-temperature correlations are high. This is consistent 

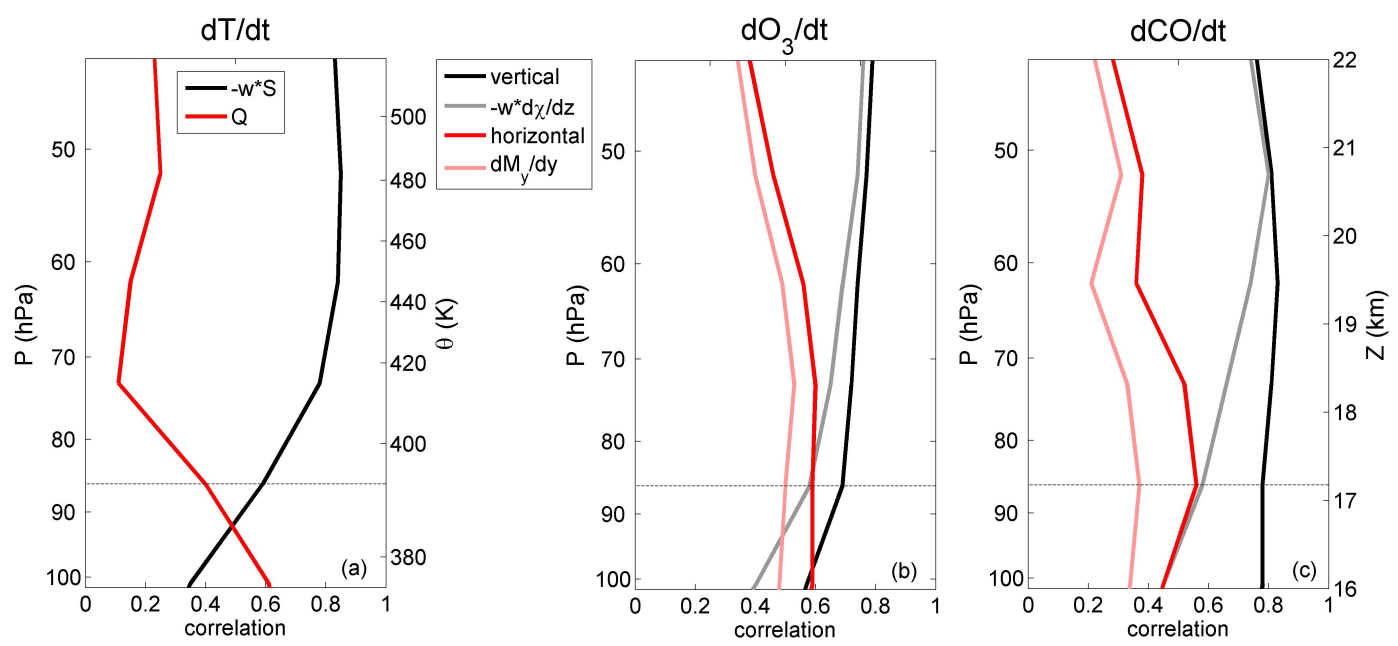

Fig. 13. Correlations between tendencies and forcings for tropical sub-seasonal variability in WACCM. (a) Correlations between sub-seasonal temperature tendency $(\partial \bar{T} / \partial t)$ and vertical advection by tropical upwelling (solid black line). The red line shows correlations of $\partial \bar{T} / \partial t$ with the diabatic heating rates $(\bar{Q})$. (b) and (c) Correlations of vertical (black) and horizontal (red) components of transport with ozone (b) and $\mathrm{CO}$ (c) tendencies. Lines in the washed colors indicate correlations of the tendency with the component that makes the largest contribution to each transport term (tropical upwelling for vertical transport and eddy term for horizontal transport). All series are filtered to isolate subseasonal timescales (that is, periods $<1 \mathrm{yr}$ ) before computing the correlations. For reference, the location of annual mean isentropic levels in WACCM is indicated on (a) and the approximate altitude on (c), estimated as described in Fig. 1. The dashed horizontal lines indicate the location of the annual mean cold point tropopause in WACCM.

with the fact that on isentropes the fraction of tracer variability that is common with temperature (forced mainly by upwelling) is removed. Because the (relatively large) component of variability tied to the adiabatic component of upwelling is removed in isentropic coordinates, the remaining tracer variability is best correlated with isentropic (quasihorizontal) eddy transport (results not shown). The contribution of isentropic transport is relatively less important for $\mathrm{CO}$ than for ozone (consistent with smaller meridional gradients in $\mathrm{CO}$ ) and the correlations with cross- and isentropic transport are comparable.

\section{Summary and discussion}

A free-running simulation from WACCM (version 4) is shown to represent the most relevant aspects of temperature, ozone and CO spatial structure and temporal variability near the tropical tropopause. One caveat is that the tropopause is slightly higher in the model and the pressure levels do not correspond to exactly the same levels in the atmosphere in terms of temperature and tracer variability.

The shift in the tropopause height is likely associated with the limited vertical resolution of the model (e.g. Gettelman et al., 2010). We have compared the vertical structure of temperature and tracer mean values and annual amplitudes (Figs. 1 and 4) with results from a high-vertical resolution $(\sim 300 \mathrm{~m})$ simulation with WACCM version 3 , similar to that used in the last CCMVal report (SPARC CCMVal, 2010). The bias in the annual mean cold point tropopause height practically disappears when the vertical resolution is increased. In addition, the shift in the altitude of maximum annual amplitude is largely reduced, especially for ozone. This comparison (not shown) proves that the model is able to capture the altitude of the tropopause more realistically than it appears when using the usual (coarser) resolution. Furthermore, it suggests that increasing the vertical resolution in the model could help improve the representation of tracer transport processes near the tropical tropopause.

Despite the described shift, the overall vertical structure and annual cycle of the temperature and tracer variability is realistically captured, and the model constitutes a valuable tool for tracer transport studies. We use WACCM results to quantify all the terms in the tracer budgets and analyze the different transport mechanisms determining the mean structure and variability on seasonal and sub-seasonal timescales. The time-mean picture shows that the budget of ozone in the tropical lower stratosphere is a balance of mean vertical advection with photochemical ozone production plus significant positive tendencies from eddy transport from the subtropics. These results support the observational analysis of Abalos et al. (2012), demonstrating that the residuals in their tracer budgets are largely associated with unresolved eddy transport terms.

Eddy transport is important for tropical ozone in the lower stratosphere, and has an interesting vertical structure in the model. At higher levels ( $\sim 440 \mathrm{~K})$ eddy transport occurs in the sub-tropics during winter and spring in each hemisphere, on the upper flanks of the subtropical jets. On the other hand, 
at levels closer to the tropopause $(\sim 400 \mathrm{~K})$ horizontal transport of ozone is dominated by the Asian monsoon anticyclonic circulation in NH summer. The vertical advection by tropical upwelling shows a large annual cycle at the higher levels (around $\sim 70 \mathrm{hPa}$, coinciding with stronger vertical gradients), and mainly drives the ozone seasonality at these altitudes. Close to the tropopause, the seasonality in vertical advection is smaller and instead there is a larger annual cycle in horizontal transport (Fig. 11). For CO, vertical transport dominates the seasonal cycle and effects of horizontal transport are less important than for ozone. A semi-annual cycle is observed at the tropopause level, linked to seasonally and spatially dependent $\mathrm{CO}$ emissions.

A number of modeling studies have examined the vertical structure and seasonality of quasi-horizontal eddy transport between the tropics and extra-tropics in the lower stratosphere (Chen et al., 1994; Volk et al., 1996; Waugh, 1996). One common conclusion of these studies is that the largest exchange occurs near the tropopause during boreal summer, mainly associated with wave activity linked to monsoonal circulations. Observational studies have also identified the near-tropopause transport associated with the Asian monsoon (e.g. Trepte et al., 1993). Large boreal summer ozone in-mixing rates derived from trajectory calculations in Ploeger et al. (2012) are observed in the layer $\sim 370-420 \mathrm{~K}$. At higher levels the tropics are more isolated and transport events are associated with breaking Rossby waves during the winter season (Waugh, 1996). Haynes and Shuckburgh (2000a, b) presented a detailed analysis of the seasonality and spatial structure of mixing throughout the upper troposphere and the stratosphere, and their results show enhanced mixing in the summer northern tropics below $\sim 400 \mathrm{~K}$. The vertical confinement of the horizontal mixing effect of the summer monsoon anticyclones to levels close to the tropopause obtained with WACCM calculations is in agreement with these previous works. On the other hand, at higher levels ( $\sim 450 \mathrm{~K})$ Haynes and Shuckburgh $(2000 \mathrm{a}, \mathrm{b})$ observed a latitudinal displacement of the tropical reservoir (identified as the region with near-zero mixing) towards the summer hemisphere, slightly more pronounced in boreal summer. They argued that this marked seasonality in the location of the subtropical transport barriers is a key issue for understanding spatial and temporal distribution of mixing in the tropical lower stratosphere. A similar seasonal latitudinal displacement of the tropical reservoir (i.e., the region with nearzero eddy transport) can also be identified in our results (see the upper panel of Fig. 9). The picture of tracer transport that arises from the present model analysis is also consistent with the climatology of Rossby wave breaking in the subtropics from the ERA-Interim reanalysis derived by Homeyer and Bowman (2013). Their results show enhanced transport into the tropics during northern summer (associated with the Asian monsoon) limited to levels below $\sim 420 \mathrm{~K}$, and more modest seasonality with slightly more frequent wave breaking during winter and spring above that level.
The choice of isentropic versus log-pressure vertical coordinates influences the detailed budget results, and by using both coordinate systems in this work we are able to quantify these complementary perspectives. As first discussed by Konopka et al. (2009), the amplitude of the seasonal cycle in ozone in isentropic coordinates is reduced by more than $50 \%$ compared to the amplitude on pressure levels. On isentropes, the largest (relative) annual cycle for ozone is found at levels close to the tropopause, where the Asian monsoon makes a major contribution to the summer maximum via eddy transport. At higher altitudes, where the largest annual cycles in temperature and ozone occur, approximately $2 / 3$ of the ozone seasonal variation is removed in isentropic coordinates, and the tendency is a relatively small term in the balance (Fig. 8b). In the case of CO, the seasonal amplitude is also reduced on isentropes but to a smaller degree, the vertical structure is unchanged and the overall balance remains similar (Fig. 12).

Because upwelling forces a large seasonal cycle in temperature at the same altitudes where the cycles in tracers are largest, the log-pressure coordinates allow simple understanding of the coupled seasonal cycles in tracers and temperature. The use of these two different vertical coordinates accounts for part of the existing discrepancy regarding the origin of the ozone seasonality. However, it remains an open question how to reconcile the Eulerian-based results in this study with the Lagrangian transport calculations of Konopka et al. (2009, 2010) and Ploeger et al. (2012).

Finally, the model simulation also reveals variability on sub-seasonal timescales in tropical lower stratosphere tracers, which are strongly correlated with temperature for ozone and anti-correlated for $\mathrm{CO}$. These coupled variations mainly result from the corresponding transient fluctuations in upwelling (Fig. 13). At levels close to the tropopause, there is also an important contribution from horizontal eddy transport for ozone and from vertical eddy transport for $\mathrm{CO}$. The variability linked to adiabatic tropical upwelling is removed on isentropic coordinates, and the (considerably smaller) subseasonal fluctuations in the tracers are mostly due to eddy quasi-horizontal (isentropic) transport events, especially for ozone. 


\section{Appendix A}
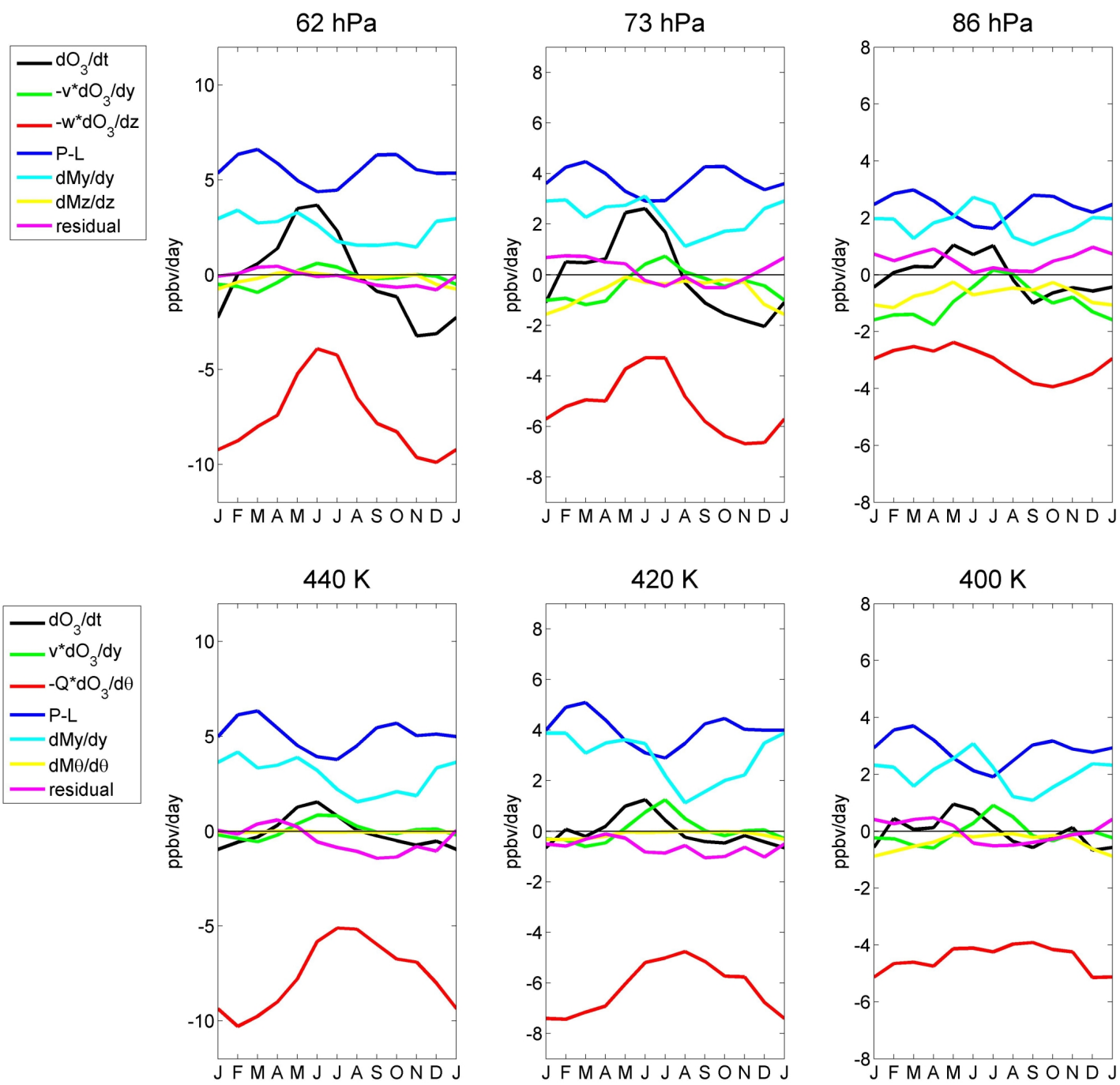

(b)

Fig. A1. Mean seasonal cycle (monthly means) of the terms in the ozone continuity equation averaged over $18^{\circ} \mathrm{S}-18^{\circ} \mathrm{N}$ on pressure levels (Eq. 2, a) and isentropic levels (Eq. 6, b). 

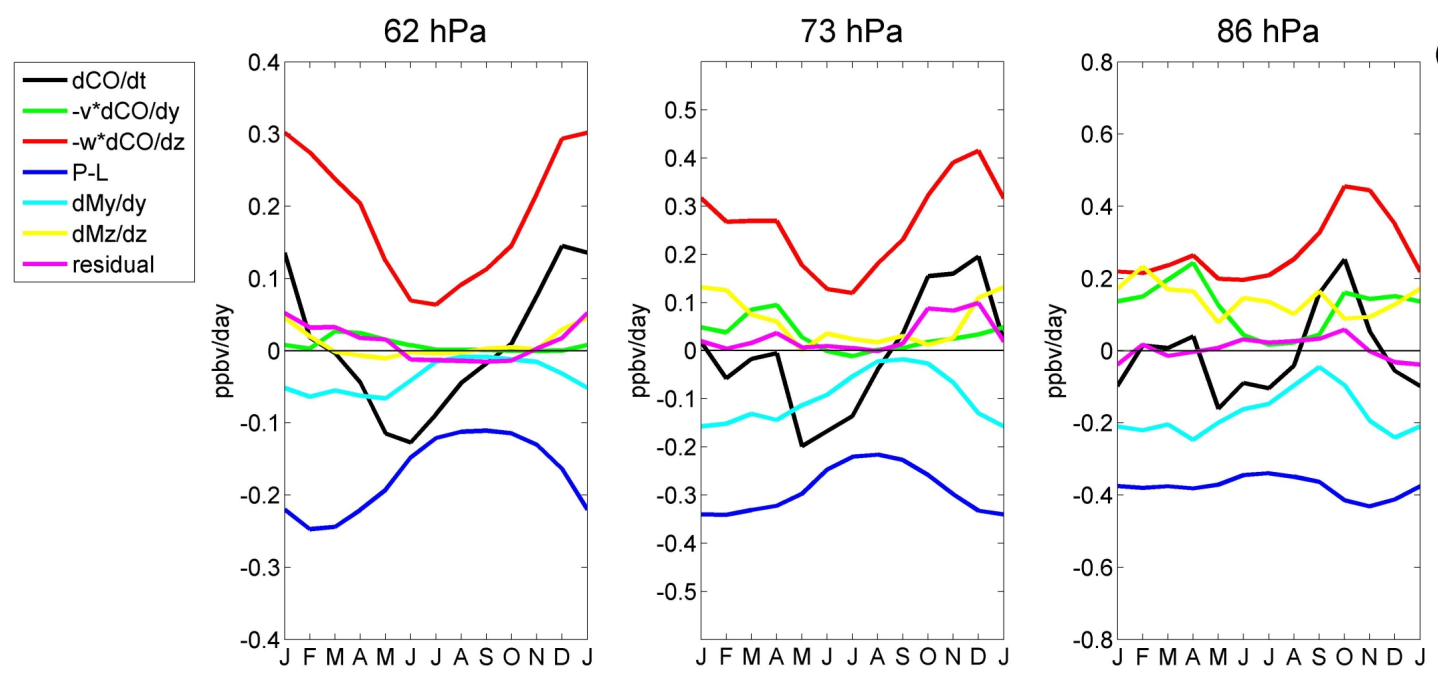

(a)
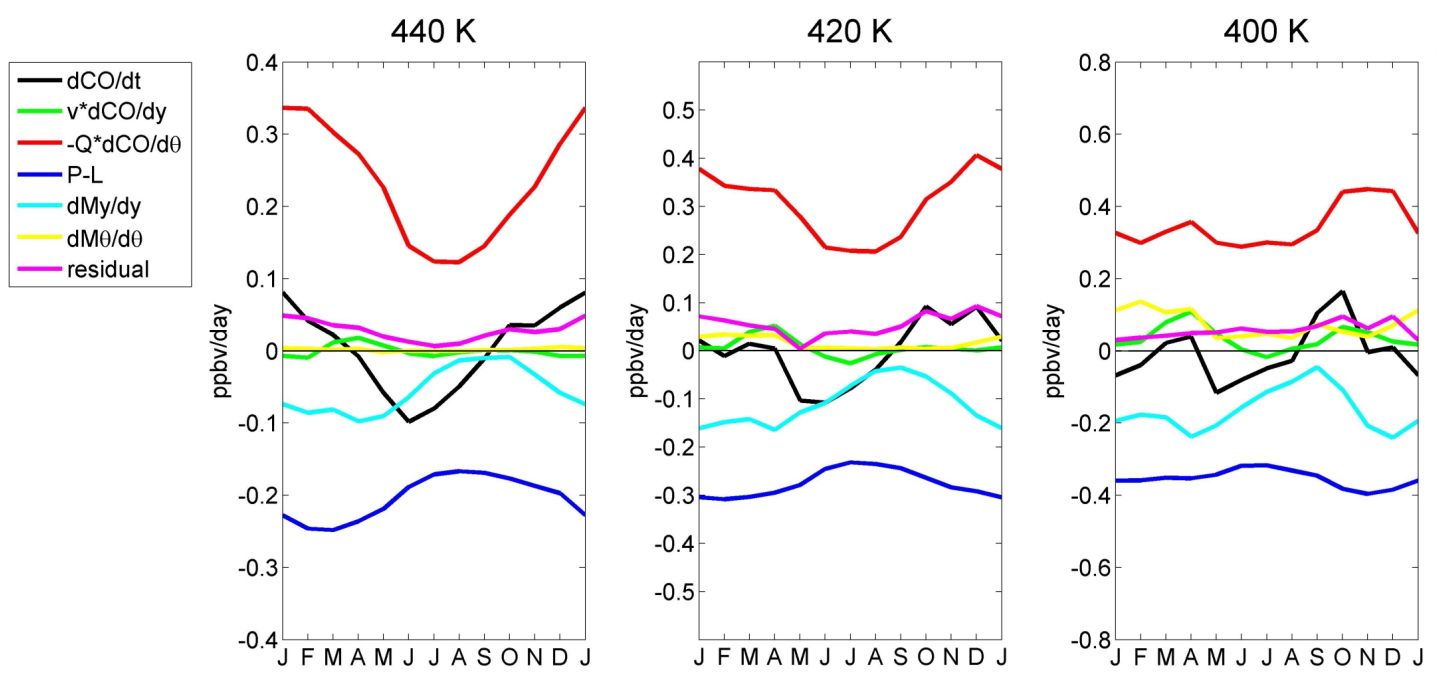

(b)

Fig. A2. Mean seasonal cycle (monthly means) of the terms in the CO continuity equation averaged over $18^{\circ} \mathrm{S}-18^{\circ} \mathrm{N}$ on pressure levels (Eq. 2, a) and isentropic levels (Eq. 6, b).

Acknowledgements. We are grateful to R. Garcia and C. Homeyer for constructive comments on the manuscript. We also thank F. Wu and M. Park for providing observational data, and J. A. Añel for facilitating the high-vertical resolution WACCM output. This work was partially supported under the NASA Aura Science Program. The National Center for Atmospheric Research is operated by the University Corporation for Atmospheric Research, under sponsorship of the National Science Foundation. Marta Abalos is funded by the grant BES-2009-013082 and the CGL2012-34997 Project of the Spanish Government. Most of the work has been carried out during visits of M. A. to the Atmospheric Chemistry Division at NCAR.

Edited by: P. Haynes

\section{References}

Abalos, M., Randel, W. J., and Serrano, E.: Variability in upwelling across the tropical tropopause and correlations with tracers in the lower stratosphere, Atmos. Chem. Phys., 12, 11505-11517, doi:10.5194/acp-12-11505-2012, 2012.

Andrews, D. G., Holton, J. R., and Leovy, C. B.: Middle Atmosphere Dynamics, Academic Press, Orlando, Florida, 489 pp., 1987.

Anthes, R. A., Bernhardt, P. A., Chen, Y., Cucurull, L., Dymond, K. F., Ector, D., Healy, S. B., Ho, S.-P., Hunt, D. C., Kuo, Y.-H., Liu, H., Manning, K., McCormik, C., Meehan, T. K., Randel, W. J., Rocken, C., Schreiner, W. S., Sokolovskiy, S. V., Syndergaard, S., Thompson, D. C., Trenberth, K. E., Wee, T.-K., Yen, N. L., 
and Zeng, Z.: The COSMIC/FORMOSAT-3 Mission: Early Results, B. Am. Meteorol. Soc., 89, 313-333, doi:10.1175/BAMS89-3-313, 2008.

Chen, P., Holton, J. R., O’Neill, A., and Swinbank, R.: Isentropic mass exchange between the Tropics and extra-tropics in the stratosphere, J. Atmos. Sci., 51, 3006-3018, 1994.

Fueglistaler, S., Dessler, A. E., Dunkerton, T. J., Folkins, I., Fu, Q., and Mote, P. W.: Tropical Tropopause Layer, Rev. Geophys., 47, RG1004, doi:10.1029/2008RG000267, 2009.

Garcia, R. R., Marsh, D. R., Kinnison, D. E., Boville, B. A., and Sassi, F.: Simulation of secular trends in the middle atmosphere, J. Geophys. Res., 112, D09301, doi:10.1029/2006JD007485, 2007.

Gettelman, A., Hegglin, M. I., Son, S.-W., Kim, J., Fujiwara, M., Birner, T., Kremser, S., Rex, Añel, J. A., Akiyoshi, H., Austin, J., Bekki, S., Braesike, P., Brül, C., Butchart, N., Chipperfield, M., Dameris, M., Dhomse, S., Garny, H., Hardiman, S. C., Jöckel, P., Kinnison, D. E., Lamarque, J. F., Mancini, E., Marchand, M., Michou, M., Morgenstern, O., Pawson, S., Pitari, G., Plummer, D., Pyle, J. A., Rozanov, E., Scinocca, J., Shepherd, T. G., Shibata, K., Smale, D, Teyssèdre, H., and Tian, W.: Multimodel assessment of the upper troposphere and lower stratosphere: Tropics and global trends, J. Geophys. Res., 115, D00M08, doi:10.1029/2009JD013638, 2010.

Haynes, P. and Shuckburgh, E.: Effective diffusivity as a diagnostic of atmospheric transport: 1. Stratosphere, J. Geophys. Res., 105, 22777-22794, doi:10.1029/2000JD900093, 2000a.

Haynes, P. and Shuckburgh, E.: Effective diffusivity as a diagnostic of atmospheric transport: 2. Troposphere and lower stratosphere, J. Geophys. Res., 105, 22795-22810, doi:10.1029/2000JD900092, 2000b.

Homeyer, C. R. and Bowman, K. P.: Rossby wavebreaking and transport between the tropics and extra-tropics above the subtropical jet, J. Atmos. Sci., 70, 607-626, doi:10.1175/JAS-D-120198.1, 2013.

Kinnison, D. E., Brasseur, G. P., Walters, S., Garcia, R. R., Marsh, D. R., Sassi, F., Harvey, V. L., Randall, C. E., Emmons, L., Lamarque, J. F., Hess, P., Orlando, J., Tie, X., Randel, W., Pan, L., Gettelman, A., Granier, C., Diehl, T., Niemeier, U., and Simmons, A. J.: Sensitivity of chemical tracers to meteorological parameters in the MOZART-3 chemical transport model, J. Geophys. Res., 112, D20302, doi:10.1029/2006JD007879, 2007.

Konopka, P., Grooß, J.-U., Ploeger, F., and Müller, R.: Annual cycle of horizontal in-mixing into the lower tropical stratosphere, J. Geophys. Res., 114, D19111, doi:10.1029/2009JD011955, 2009.

Konopka, P., Grooß, J.-U., Günther, G., Ploeger, F., Pommrich, R., Müller, R., and Livesey, N.: Annual cycle of ozone at and above the tropical tropopause: observations versus simulations with the Chemical Lagrangian Model of the Stratosphere (CLaMS), Atmos. Chem. Phys., 10, 121-132, doi:10.5194/acp-10-121-2010, 2010.

Lin, S.-J.: A "vertically lagrangian" finite-volume dynamical core for global models, Mon. Weather Rev., 132, 2293-2307, doi:10.1175/1520-0493(2004)132<2293:AVLFDC>2.0.CO;2, 2004.

Liu, J., Logan, J. A., Murray, L. T., Pumphrey, H. C., Schwartz, M. J., and Megretskaia, I. A.: Transport analysis and source attribution of seasonal and interannual variability of $\mathrm{CO}$ in the tropical upper troposphere and lower stratosphere, Atmos. Chem. Phys., 13, 129-146, doi:10.5194/acp-13-129-2013, 2013.

Livesey, N. J., Filipiak, M. J., Froidevaux, L., Read, W. G., Lambert, A., Santee, M. L., Jiang, J. H., Pumphrey, H. C., Waters, J. W., Cofield, R. E., Cuddy, D. T., Daffer, W. H., Drouin, B. J., Fuller, R. A., Jarnot, R. F., Jiang, Y. B., Knosp, B. W., Li, Q. B., Perun, V. S., Schwartz, M. J., Snyder, W. V., Stek, P. C., Thurstans, R. P., Wagner, P. A., Avery, M., Browell, E. V., Cammas, J.-P., E. Christensen, L., Diskin, G. S., Gao, R.-S., Jost, H.-J., Loewenstein, M., Lopez, J. D., Nedelec, P., Osterman, G. B., Sachse, G. W., and Webster, C. R.: Validation of Aura Microwave Limb Sounder $\mathrm{O}_{3}$ and $\mathrm{CO}$ observations in the upper troposphere and lower stratosphere, J. Geophys. Res., 113, D15S02, doi:10.1029/2007JD008805, 2008.

Park, M., Randel, W. J., Kinnison, D. E., Emmons, L. K., Bernath, P. F., Walker, K. A., Boone, C. D. D., and Livesey, N. J.: Hydrocarbons in the upper troposphere and lower stratosphere observed from ACE-FTS and comparisons with WACCM, J. Geophys. Res., doi:10.1029/2012JD018327, in press, 2013.

Ploeger, F., Konopka, P., Müller, R., Fueglistaler, S., Schmidt, T., Manners, J. C., Grooß, J.-U., Günther, G., Forster, P. M., and Riese, M.: Horizontal transport affecting trace gas seasonality in the Tropical Tropopause Layer (TTL), J. Geophys. Res., 117, 116, doi:10.1029/2011JD017267, 2012.

Plumb, R. A.: A tropical pipe model of stratospheric transport, J. Geophys. Res., 101, 3957-3972, doi:10.1029/95JD03002, 1996.

Plumb, R. A.: Stratospheric transport, J. Meteorol. Soc. Jpn., 80, 793-809, doi:10.2151/jmsj.80.793, 2002.

Randel, W. J. and Held, I. M.: Phase speed spectra of transient eddy fluxes and critical layer absorption, J. Atmos. Sci., 48, 688-697, doi:10.1175/1520-0469(1991)048<0688:PSSOTE>2.0.CO;2, 1991.

Randel, W. J., Park, M., Wu, F., and Livesey, N.: A Large Annual Cycle in Ozone above the Tropical Tropopause Linked to the Brewer-Dobson Circulation, J. Atmos. Sci., 64, 4479-4488, doi:10.1175/2007JAS2409.1, 2007.

Riese, M., Ploeger, F., Rap, A., Vogel, B., Konopka, P., Dameris, M., and Forster, P.: Impact of uncertainties in atmospheric mixing on simulated UTLS composition and related radiative effects, J. Geophys. Res., 117, 1-10, doi:10.1029/2012JD017751, 2012.

Rosenlof, K. H., Tuck, A. F., Kelly, K. K., Russell III, J. M., and McCormick, M. P.: Hemispheric asymmetries in water vapor and inferences about transport in the lower stratosphere, J. Geophys. Res., 102, 13213-13234, doi:10.1029/97JD00873, 1997.

Santee, M. L., Manney, G. L., Livesey, N. J., Froidevaux, L., Schwartz, M. J., and Read, W. G.: Trace gas evolution in the lowermost stratosphere from Aura Microwave Limb Sounder measurements, J. Geophys. Res., 116, D18306, doi:10.1029/2011JD015590, 2011.

Shepherd, T. G.: Transport in the middle atmosphere, J. Meteorol. Soc. Jpn., 85, 165-191, 2007.

SPARC CCMVal Report on the Evaluation of Chemistry-Climate Models, Eyring, V., Shepherd, T. G., and Waugh, D. W. (Eds.), SPARC Report No. 5, WCRP-132, WMO/TD-No. 1526, 2010.

Taguchi, M.: Wave driving in the tropical lower stratosphere as simulated by WACCM. Part I: annual cycle, J. Atmos. Sci., 66, 2029-2043, doi:10.1175/2009JAS2854.1, 2009.

Thompson, A. M., Witte, J. C., Smit, H. G. J., Oltmans, S. J., Johnson, B. J., Kirchhoff, V. W. J. H., and Schmidlin, F. J.: Southern 
Hemisphere Additional Ozonesondes (SHADOZ) 1998-2004 tropical ozone climatology: 3. Instrumentation, station-to-station variability, and evaluation with simulated flight profiles, J. Geophys. Res., 112, D03304, doi:10.1029/2005JD007042, 2007.

Thompson, A. M., Miller, S. K., Tilmes, S., Kollonige, D. W., Witte, J. C., Oltmans, S. J., Johnson, B. J., Fujiwara, M., Schmidlin, F. J., Coetzee, G. J. R., Komala, N., Maata, M., Mohamad, M., Nguyo, J., Mutai, C., Ogino, S.-Y., da Silva, F. R., Paes Leme, N. M., Posny, F., Scheele, R., Selkirk, H. B., Shiotani, M., Stübi, R., Levrat, G., Calpini, B., Thouret, V., Tsuruta, H., Valverde Canossa, J., Vömel, H., Yonemura, S., Diaz, J. A., Tan Thanh, N. T., and Thuy Ha, H. T.: Southern Hemisphere Additional Ozonesondes (SHADOZ) ozone climatology (2005-2009): Tropospheric and tropical tropopause layer (TTL) profiles with comparisons to OMI-based ozone products, J. Geophys. Res., 117, D23301, doi:10.1029/2011JD016911, 2012.
Trepte, C. R., Veiga, R. E., and McCormick, M. P.: The poleward dispersal of Mount Pinatubo volcanic aerosol, J. Geophys. Res., 98, 18563-18573, doi:10.1029/93JD01362, 1993.

Volk, C. M., Elkins, J. W., Fahey, D. W., Salawitch, R. J., Dutton, G. S., Gilligan, J. M., Proffitt, M. H., Loewenstein, M., Podolske, J. R., Minschwaner, K., Margitan, J. J., and Chang, K. R.: Quantifying transport between the tropical and mid-latitude lower stratosphere, Science, 272, 1763-1768, doi:10.1126/science.272.5269.1763, 1996.

Waugh, D. W.: Seasonal variation of isentropic transport out of the tropical stratosphere, J. Geophys. Res., 101, 4007-4023, doi:10.1029/95JD03160, 1996. 